\title{
Medidas Correctivas a los Impactos Ambientales en la Carretera Cusco Quillabamba: Tramo Abra de Málaga-Alfamayo
}

\section{Corrective Measures to Environmental Impacts on the Cusco Quillabamba Highway: Abra Malaga-Alfamayo Section}

\author{
Juan Eduardo Gil-Mora $^{1^{*}}$ \& Berioska Sosa-Aguirre ${ }^{2}$ \\ ${ }^{1}$ Blgo. M. Sc. En Ciencia y Tecnología Ambiental; docente Escuela de Posgrado Universidad San Antonio \\ Abad del Cusco \\ ${ }^{2}$ Berioska Sosa Aguirre. Ing. Ambiental \\ *Correo electronico:mundoandino2005@yahoo.es
}

\section{Resumen}

La carretera Cusco-Quillabamba (Perú), es una de las más importantes vías en la región Cusco. El estudio se realizó en el tramo Abra Malaga-Alfamayo, de $29 \mathrm{Km}$ de longitud que atraviesa zonas de vida ricas en biodiversidad y una geología con fracturamientos y constituye una zona crítica y vulnerable debido al inadecuado manejo e inapropiada implementación del Plan de manejo Ambiental en la etapa de operación, generando problemas sociales, ambientales y económicos. La investigación se desarrolló utilizando el método exploratorio y descriptivo y metodologías para la mensuración en campo de indicadores (peralte, taludes, EIA); se evaluó los impactos ambientales en la etapa de operación y se tiene que el $100 \%$ de los peraltes no están ceñidos a la normatividad nacional; los taludes en el tramo son superiores a $70^{\circ}$ por lo que generan deslizamientos y desprendimientos de rocas y sedimentos; los métodos aplicados para medir los impactos ambientales, señalan impactos negativos a la biodiversidad, calidad del aire, agua y suelo. Conocido los impactos negativos y que éstos reversibles, plantea la implementación de medidas correctivas a los impactos ambientales en el tramo, como la revegetación con especies nativas, construcción de pases para fauna, que permitan la conservación de la biodiversidad en la zona y la transitabilidad.

Palabras clave: biodiversidad, impacto, mitigación, peralte, talud. 


\begin{abstract}
The Cusco-Quillabamba highway (Peru) is one of the most important roads in the Cusco region. The study was carried out on the section Abra MalagaAlfamayo, $29 \mathrm{~km}$ long that crosses natural life zones rich in biodiversity and a geology with fractures and constitutes a critical and vulnerable zone due to inadequate management and inappropriate implementation of the Environmental Management Plan in the operation stage, generating social, environmental and economic problems. The research was developed using the exploratory and descriptive method and methodologies for the measurement in the field of indicators (cant, slopes, EIA); The environmental impacts were evaluated in the operation stage and it is found that $100 \%$ of the cans are not bound by national regulations; the slopes in the section are higher than $70^{\circ}$ so they generate landslides and rockslides and sediments; the methods applied to measure environmental impacts indicate negative impacts on biodiversity, air, water and soil quality. Knowing the negative impacts and that they are reversible, it proposes the implementation of corrective measures to the environmental impacts in the section, such as revegetation with native species, construction of passes for fauna, which allow the conservation of the biodiversity in the area and a normal road traffic.
\end{abstract}

Key words. biodiversity, cant, impact, mitigation, slope.

\title{
Introducción
}

Las carreteras son inversiones importantes que demandan atención permanente a través de trabajos de mantenimiento para estar en buenas condiciones y ser transitables durante el año. Las vías de comunicación requieren el aseguramiento de la calidad, como la garantía del servicio y la seguridad, tanto en el factor humano como en el ambiental. En el Perú esto está señalado en la Ley del Sistema Nacional de Evaluación del Impacto Ambiental N 27446 y su Reglamento (Ministerio del Ambiente-MINAM, 2009).

El Impacto Ambiental es definido (Conesa, 2010) como un procedimiento analítico orientado a formar un juicio objetivo sobre las consecuencias de los impactos derivados de la ejecución de una determinada actividad. Para Canter (1998), es todo procedimiento para la identificación y valoración de los impactos potenciales de proyectos, relativos a los componentes físico-químicos, bióticos, culturales y socioeconómicos del entorno. En el Perú, de acuerdo con el Decreto Supremo N 019-2009-MINAM (Reglamento de La Ley $\mathrm{N}^{\circ}$ 27446, Ley del Sistema Nacional de Evaluación de Impacto Ambiental), la evaluación de impacto ambiental es un proceso participativo, técnico administrativo, destinado a prevenir, minimizar, corregir y/o mitigar e informar acerca de los potenciales impactos ambientales negativos que pudieran derivarse de las políticas, planes, programas y proyectos de inversión, y asimismo, intensificar sus impactos positivos. 
De otro lado, el Reglamento de la Ley 27446, señala que los planes de manejo ambiental son instrumentos producto de una evaluación ambiental que, de manera detallada, establece las acciones que se implementarán para prevenir, mitigar, rehabilitar o compensar los impactos negativos que cause el desarrollo de un proyecto, obra o actividad. Incluye los planes de relaciones comunitarias, monitoreo, contingencia y abandono según la naturaleza del proyecto, obra o actividad. Según el anexo III del Reglamento de la Ley $N^{\circ} 27446$ la estrategia de manejo ambiental debe describir los siguientes lineamientos: a. El plan de manejo ambiental donde se identifican y caracterizan todas las medidas a realizar para prevenir, mitigar y/o corregir los impactos ambientales identificados. b. El plan de vigilancia ambiental y los mecanismos para su implementación, estableciendo responsabilidades específicas para asegurar el cumplimiento de las medidas establecidas en el plan de manejo ambiental. En este plan debe incluirse la vigilancia ambiental y el programa de monitoreo ambiental, que señale las acciones para el cumplimiento de los límites máximos permisibles u otros establecidos en las normas nacionales vigentes, para el monitoreo de las residuos líquidos, sólidos y gaseosos.

De conformidad con el Ministerio de Transportes y Comunicaciones-MTC (2005a, b, c) y la Ley 27446, Ley del Sistema Nacional de Evaluación de Impacto Ambiental (MINAM, 2011), los proyectos viales deben adecuarse a la legislación Ambiental. La carretera Cusco-Quillabamba se encuentra en la etapa de operación y en su trayecto se observa falta de adecuado y oportuno mantenimiento; fallas en el diseño de la vía, deslizamientos, erosión, afectación a la flora y fauna, deterioro y perdida de la carpeta de rodadura, disminución en la efectividad de las cunetas laterales, de los pontones y sistemas de drenaje, deterioro en las cunetas de coronación, no manejo de micro-cuencas y riachos temporales y permanentes, que conducen a impactos sociales, económicos y ambientales evaluados en la investigación.

Al evaluar los impactos de la carretera en la etapa de funcionamiento se contrasta la información secundaria del proyecto carretero proporcionado por la Dirección Regional de Transportes y Comunicaciones (MTC, 2005d) con las observaciones y mediciones de campo y el objetivo es alcanzar medidas correctivas, cuya finalidad es la recuperación, total o parcial, de las condiciones existentes y que ocasionan los impactos ambientales.

La diversidad biológica representa al medio biológico, y según el Convenio Internacional sobre la Diversidad Biológica (2010) comprende la variedad de ecosistemas y las diferencias genéticas dentro de cada especie que permiten la combinación de múltiples formas de vida. Según Constanza et al (1997), el valor esencial y fundamental de la biodiversidad reside en que es resultado de un proceso histórico natural de gran antigüedad. Por esta sola razón, la diversidad biológica tiene el inalienable derecho de continuar su existencia.

De acuerdo al Banco Interamericano de Desarrollo (BID, 1997), los EIA deberán incluir, evaluación previa y caracterización de impactos, así como la opción de alternativa sin proyecto; de otro lado, esta misma organización, en referencia a ecosistemas frágiles como las que se hallan en el tramo carretero en estudio, considera que, si un lugar es fundamental para la viabilidad de las rutas de migración de una especie, es un hábitat natural de importancia crítica. Los viajes de las especies migratorias desde una zona geográfica hacia otra tienen carácter cíclico y son predecibles. Los proyectos de infraestructura lineales, como las carreteras pueden pasar a través de rutas migratorias 
y crear obstáculos (BID, 2015). Por lo tanto, todo proyecto vial debe de considerar la biodiversidad local.

Entre los efectos ecológicos más significativos de las carreteras se citan: fragmentación de ecosistemas, dispersión de especies exóticas y disminución de las poblaciones de especies de flora y fauna nativas, alteración del ciclo hidrológico, cambios microclimáticos, producción de material particulado y de ruido, y contaminación de las aguas y del suelo. La apertura de frentes de colonización es un impacto indirecto que puede generar en el mediano y largo plazo la reconversión en el uso del suelo, la destrucción de hábitats naturales y la reducción de la biodiversidad.

La fragmentación ocurre cuando un hábitat amplio y continuo se reduce y se subdivide en dos o más fragmentos. Este fenómeno ocurre cuando el área es atravesada por una carretera y divida el área (Primack, 1998). Si bien al construir una carretera el área afectada de modo directo puede ser relativamente pequeña, la fragmentación del hábitat tiene dos efectos principales que amenazan la persistencia de las especies, denominados el efecto barrera y el efecto de borde. Según Primack (1998), las vías rompen la continuidad del dosel (estrato superior de los bosques) e interrumpen las posibilidades de movilidad de los animales. Las barreras también pueden restringir la habilidad de los organismos de encontrar sus parejas, lo que puede llevar a la pérdida de su potencial reproductivo.

El efecto de borde se presenta cuando un ecosistema es fragmentado y se cambian las condiciones bióticas y abióticas de los fragmentos y de la matriz circundante (Kattan, 2002). En el caso de carreteras este efecto se presenta en las inmediaciones o borde de la vía, donde se crean condiciones con mayor temperatura, menor humedad, mayor radiación y mayor susceptibilidad al viento. Según lo reportado por Goosem (2002), este efecto de borde puede penetrar $50 \mathrm{~m}$ para aves, $100 \mathrm{~m}$ para los efectos microclimáticos y $300 \mathrm{~m}$ para insectos.

Se han llevado a cabo diversos estudios en donde se comprueba efectivamente que las densidades poblacionales del 60\% de las especies de bosques y pastizales que viven cerca de los bordes de carreteras son inferiores a las densidades localizadas lejos de ellas (Reijnen et al., 1996). Similarmente, Ortega y Capen (1999) reportaron que la población de horneros (una especie de ave sensible a la fragmentación) era menor en los fragmentos de bosques cercanos a las carreteras que en los distantes, por causa del efecto de borde.

El ruido generado por el tránsito vehicular es uno de los factores que mayores impactos ecológicos causan a la fauna, puesto que produce varios efectos como el desplazamiento, reducción de áreas de actividad y un bajo éxito reproductivo, lo que está asociado a la pérdida de la capacidad auditiva, aumento de las hormonas del estrés, comportamientos alterados e interferencias en la comunicación durante la época reproductiva, entre otros (Forman y Alexander, 1998).

Los EIA identifican la presencia de especies endémicas, amenazadas o en peligro de extinción en el área de influencia de los proyectos y recomienda la realización de estudios complementarios que permiten evaluar el estado de las mismas (Liberman et al. 2000).

La Corporación Andina de Fomento (CAF, 2018), al considerar la vinculación entre la infraestructura vial y los factores climáticos, señala: La variabilidad y cambio climáticos tiene consecuencias significativas en las infraestructuras viarias. Debido a la 
duración de la vida útil de las carreteras, que superan los 50 años, no sólo son sensibles al clima en el momento de su construcción, sino también a las variaciones del clima décadas después. Por lo tanto, para aumentar la resiliencia de las carreteras ya en servicio debería gestionarse adecuadamente el impacto que el clima puede producir en ellas a lo largo de su vida útil, aspectos que son analizados en el tramo carretero en estudio.

Sánchez (2002) especifica que, una vez aprobados los EIA, deberá acompañarse de la implementación de todas las medidas dirigidas a reducir, eliminar o compensar los impactos negativos, o potenciar los positivos. Lo mismo deberá ser observado durante las fases de funcionamiento y desactivación.

Los objetivos de la investigación fueron: Evaluar los impactos generados en la etapa de operación del tramo carretero Abra Málaga-Alfamayo (Cusco, Perú), que incluye el mantenimiento o conservación de la carpeta de rodadura, para proponer acciones correctivas y mitigar los impactos ambientales negativos; mensurar los efectos e impactos en campo y sugerir acciones correctivas para mitigar, restaurar y minimizar los impactos negativos.

Cabe manifestar que, en el tramo carretero Abra Málaga-Alfamayo, se ha observado deterioro de la vía por el inadecuado mantenimiento y la inapropiada implementación del Plan de Manejo Ambiental en la etapa de construcción, como consecuencia, pueden generar impactos ambientales, sociales y económicos negativos que han sido evaluados y que son necesarios corregir.

\section{Metodología}

Se utilizó la investigación exploratoria (Hernández et al, 2013), en razón a que el objetivo es examinar el problema objeto de investigación que ha sido poco estudiado y no fue abordado adecuadamente; igualmente la investigación es descriptiva (Hernández et al 1991), debido a que busca especificar las características de los impactos generados por la falta de cumplimiento de los planes de manejo ambiental en la etapa de operación del tramo carretero y sea sometido a análisis para alcanzar sugerencias.

La metodología utilizada se dio en etapas para la obtención de una herramienta de evaluación de impacto ambiental aplicada a la fase de funcionamiento del tramo carretero en estudio. Se procedió con las siguientes etapas metodológicas:

Etapa 1. Caracterización del proyecto de infraestructura. Consistió en la obtención de información secundaria, específicamente del Plan de Manejo Ambiental del proyecto. Para esto se revisaron los términos de referencia otorgados por el MTC (Ministerio de Transportes y Comunicaciones), MINAM (Ministerio del Ambiente) y otras instituciones vinculadas al estudio de impactos ambientales en proyectos viales, así como lo dispuesto por el MINAM (2009) mediante Decreto Supremo N 019-2009-MINAM (Reglamento de La Ley No 27446, Ley del Sistema Nacional de Evaluación de Impacto Ambiental). El Anexo V de dicho Reglamento especifica los criterios de protección ambiental y la propuesta de clasificación de autores como Ángel (2010) y Arboleda (2008).

Etapa 2. Identificación de impactos ambientales. Se basó en trabajos de campo, mensuraciones in situ y la aplicación de metodologías oficiales aprobadas en el Perú por 
el MINAM mediante Resolución Ministerial N 455-2018-MINAM (MINAM, 2019). Se construyó un listado de impactos ambientales de acuerdo a las regulaciones existentes; luego, se utilizaron las matrices de interacción para la determinación y cuantificación de los impactos ambientales para identificar los de mayor incidencia sobre el entorno.

Etapa 3. Medición y evaluación para la determinación del EIA y definición de significancia ambiental. Para la selección de atributos, se identificaron indicadores que fueran: medibles (análisis cuantitativo) y, en escalas de valoración (análisis cualitativo). Un indicador de impacto ambiental es aquél que transmite información sobre el estado del factor o componente ambiental y se utiliza para determinar el cambio en la calidad ambiental asociado a una determinada acción (Gallopín, 1997, Segnestam, 2002, Garmendia et al, 2005). De acuerdo a las relaciones de causalidad pueden existir indicadores de causa que permiten identificar la situación que origina el cambio en el factor, indicadores de efecto, que permiten identificar los cambios generados en el factor y los indicadores de calidad ambiental que combinan todas las variables para determinado el estado del factor.

Etapa 4. Priorización de impactos. Mediante las hojas de campo desarrolladas, se recogió información referido a impactos, información utilizada en las matrices, cuya metodología se describe líneas abajo y, al mismo tiempo, los resultados se tradujeron en acciones correctivas sugeridas.

Las técnicas e instrumentos de recolección de información utilizadas fueron la mensuración y observación en campo, observaciones directas para la biodiversidad, mediciones directas del peralte y taludes, revisión y análisis de legislación aplicable, fichas técnicas, carta nacional, eclímetro, GPS y cinta métrica.

\section{Metodología para la Medición del Peralte}

De conformidad al Manual de diseño de carreteras no pavimentadas de bajo volumen de tránsito del MTC (2008b), se denomina peralte a la sobre elevación de la parte exterior de un tramo de la carretera en curva con relación a la parte interior del mismo con el fin de contrarrestar la acción de la fuerza centrífuga. Las curvas horizontales deben ser peraltadas. El peralte máximo tendrá como valor máximo normal $8 \%$ y como valor excepcional $10 \%$. En carreteras afirmadas bien drenadas en casos extremos, podría justificarse un peralte máximo alrededor de $12 \%$.

Se midieron las características de la curva, principalmente el peralte; luego, se verificó si ésta fue la adecuada y se comparó con la normativa vigente. El procedimiento para hallar el peralte fue colocando el eclímetro sobre la plataforma vial y se determinó el peralte (p) en porcentaje (\%); se midió el radio de la curva (R) en metros y el ancho de la plataforma vial (A) en metros; luego, se aplicó la Fórmula 1 (MTC, 2008a).

$$
V e^{2}=127 \times R\left(f_{t}+\frac{p}{100}\right)
$$

Fórmula 1. 
Donde:

Ve: Velocidad específica $(\mathrm{Km} / \mathrm{h})$, constituye la velocidad del vehículo con la que debe de ingresar a una curva a fin de evitar la fuerza centrífuga y debe de estar señalizada.

$\mathrm{R}: \operatorname{radio}(\mathrm{m})$

$\mathrm{f}_{\mathrm{t}}$ : Coeficiente de rozamiento transversal (varía entre 0.180 a $30 \mathrm{Km} / \mathrm{h}$ y 0.087 a 150 $\mathrm{Km} / \mathrm{h})$

$\mathrm{p}$ : peralte $(\%)$.

De la Fórmula 1, se despeja el peralte para su respectivo cálculo y, se tiene la Fórmula 2.

$$
p=\frac{V^{2}}{127 R}-f_{t}(100)
$$

\section{Fórmula 2.}

\section{Metodología para la Medición del Talud}

Según Bishop \& Henkel (1962), la estabilidad de un talud está determinada por factores geométricos (altura e inclinación), factores geológicos (presencia de agua) y factores geotécnicos o relacionados con el comportamiento mecánico del terreno (resistencia y deformabilidad). La combinación de estos factores puede determinar la condición de rotura a lo largo de una o varias superficies, y que sea cinemáticamente posible el movimiento de un cierto volumen de masa de suelo o roca. De otro lado, de conformidad con Ortolani (1961), los factores geológicos, hidrogeológicos y geotécnicos se consideran factores condicionantes, y son intrínsecos a los materiales naturales, en los suelos, litología, estratigrafía y las condiciones hidrogeológicas determinan las propiedades resistentes y el comportamiento del talud, en el caso de macizos rocosos, la disposición y frecuencia de las superficies de discontinuidad y el grado de fracturación; en materiales blandos, como los lutíticos o pizarrosos, la litología y el grado de alteración juegan también un papel predominante; por lo tanto, las características de los taludes son aspectos de interés a ser considerados en los estudios ambientales.

Se midieron las pendientes de los taludes con un eclímetro para conocer la inclinación. Con una cinta métrica se midieron las longitudes para conocer el riesgo que pudieran generar. Se registraron las coordenadas de las ubicaciones con un GPS.

\section{Metodología de Evaluación de Impactos Ambientales}

Se utilizaron matrices adaptadas a los objetivos del estudio como las de tipología de impactos, matriz de importancia y causa/efecto (Conesa, 1995; Canter, 1998); los resultados son analizados comparativamente. Se utilizó la técnica de listado simple para la elaboración de la matriz de identificación de impactos ambientales. Las matrices 
utilizadas para la evaluación de los impactos ambientales, como la matriz de impactos, matriz causa/efecto, matriz de importancia, y otras, fueron de conformidad a lo dispuesto por el MINAM (2012). Es pertinente señalar que los EIA tienen como objetivo identificar, describir y evaluar los efectos directos e indirectos de un proyecto sobre el ser humano, fauna y flora, así como también los bienes materiales y el patrimonio cultural (Conesa, 2010).

Liberman et al. (2000), afirma que la construcción de carreteras produce una serie de impactos ambientales en el entorno físico, biológico y social tanto en las etapas de construcción, operación y mantenimiento. El impacto causado por cambios o modificaciones en el hábitat humano y silvestre es un resultado irreversible que deben ser medidos con metodologías aplicables.

Espinoza et al (2000), sostienen que los impactos en un proyecto vial pueden ser impactos directos, aquellos que se dan desde la fase de construcción de las mismas, $y$, durante toda su vida útil; siendo las más relevantes: limpieza, nivelación, pérdida de la capa vegetal, exclusión de otros usos para la tierra, modificación de patrones naturales de drenaje, cambios en el perfil freático, deslaves, erosión y sedimentación de ríos, lagos y lagunas, interferencia con la movilización de animales silvestres, ganado y población de los territorios.

Además de ello alteración del entorno, tales como: contaminación del aire y del suelo, provenientes de las plantas de asfalto, el polvo y el ruido del equipo de construcción y de explosivos, derrame de combustibles y aceites, residuos sólidos. Impactos indirectos, atribuidos a la construcción, rehabilitación y mantenimiento de las vías terrestres. Muchas de estas son principalmente socioculturales. Estos incluyen: la degradación visual debido a la colocación de carteles a los lados del camino, los impactos de la urbanización no planificada, inducida por el proyecto; la alteración de la tenencia local de tierras, debido a la especulación; la construcción de nuevos caminos primarios, secundarios y terciarios; el mayor acceso humano a las zonas silvestres y otras áreas naturales; y la migración de la mano de obra y desplazamiento de las economías de subsistencia.

Existen también los Impactos Acumulativos que son la degradación ambiental progresiva o sinérgica, que no se manifiesta al analizar actividades de manera aislada, pero, que al visualizarlas en conjunto son visibles. Usualmente, este tipo de análisis, escapa a la competencia de la EIA, pero es responsabilidad directa de las autoridades públicas al estudiar las políticas, planes y programas, por medio de otras herramientas de gestión ambiental; como lo es, la evaluación ambiental estratégica.

\section{Metodología para la Determinación del Área de Influencia Directa e Indirecta}

El área de influencia de un proyecto, se define como la distribución espacial de los posibles impactos y efectos que generará el proyecto, (Conesa, 2010).

De conformidad con el MINAM (2011), y utilizando el método propuesto por Canter (1998), se determinó el Área de Influencia Directa (AID) que corresponde al área aledaña a la infraestructura vial, donde los impactos generados en las etapas de construcción y operación de la vía son directos, inmediatos y de mayor intensidad, y donde el entorno natural y antrópico se pueden ver afectados. De esta manera, la determinación del área de influencia en una carretera puede definirse al delimitar a lo largo de su eje un 
ancho de 200 metros a cada lado de la carretera. Por lo tanto, contando con la longitud de la carretera y el ancho de la franja, se puede obtener el área de influencia directa medido en $\mathrm{Km}^{2}$.

El Área de Influencia Indirecta (AII) se define como la extensión geográfica donde los impactos del proyecto se manifiestan de forma indirecta, ya sea en forma positiva o negativa, con una intensidad diversa en los medios físicos, biológicos, socio-económicos y culturales. De acuerdo con Dueñas et al. (2012) y Keller et al. (1995), la determinación del área de influencia indirecta en una carretera puede definirse al delimitar a lo largo de su eje un ancho de 400 metros a cada lado del AID; la delimitación del AII se calculó con los siguientes criterios:

- Áreas que no son impactadas directamente por el funcionamiento de la vía, circulación de vehículos, trabajos de mantenimiento o por establecimiento de instalaciones auxiliares para mantenimiento o por actividades antrópicas a lo largo del eje carretero.

- Áreas que experimentan impactos negativos o positivos debido a determinadas dinámicas sociales, económicas, políticas y culturales que se generan por el uso de la vía en la etapa de operación.

Con la identificación de los impactos potenciales en el tramo vial se elaboraron hojas de campo para consignar los sectores que constituyen pasivos ambientales que deberán ser remediados (MTC, 2018). La valoración de los impactos hace posible determinar su magnitud y significancia, facultando proponer medidas correctivas orientadas a eliminar o mitigar los impactos negativos (MTC, 2005d).

Los criterios para delimitar el AID han tenido en consideración las actividades previstas en la etapa de operación, el derecho de vía y el área de concesión, por lo que el AID se ha definido dentro de una franja a lo largo de la carretera, siguiendo la metodología señalada y considerando la interacción con los aspectos físicos, biológicos y sociales de su entorno.

El tramo Abra de Málaga-Alfamayo, como se muestra en la Figura 1, constituye el ámbito de estudio, posee zonas de vida natural ricas en biodiversidad, una geología frágil, pendientes superiores al 35\% (MTC, 2005e). Este tramo constituye una de las zonas críticas y vulnerables desde el punto de vista ambiental, alberga ecosistemas frágiles de puna y de bosque nuboso y la precipitación pluvial es superior a $800 \mathrm{~mm}$ en la zona alta y $1800 \mathrm{~mm}$ anuales en la zona del bosque de nubes (MTC, 2006). El tramo se inicia en el Abra Málaga, a una elevación de 4330 msnm, y termina en Alfamayo, a 3002 msnm. Pertenece a la Ruta PE-28B de la vía Cusco-Quillabamba (MTC, 2010b). El Ministerio de Economía y Finanzas, el 2006 otorgó la viabilidad al proyecto "Construcción y Mejoramiento de la Carretera Ollantaytambo-Quillabamba” (MTC, 2018); esta vía está clasificada como Red Vial Departamental o Regional, de conformidad al Decreto Supremo 017-2007-MTC (MTC, 2007). 


\section{Resultados}

\section{Determinación del Área de Influencia Directa (AID) e Indirecta (AII)}

En la Tabla 1 y Figura 2 se especifica la determinación del AID y AII.

En el tramo estudiado, el AID tiene un área de $11.6 \mathrm{Km}^{2}$ y el AII alcanza una superficie de $23.2 \mathrm{Km}^{2}$, en estos escenarios se evidencian los impactos ambientales de efecto barrera y el efecto de borde respectivamente, además de la intervención de los pobladores que son evidentes y requieren ser gestionados.

\section{Análisis de los Resultados en Peralte}

Han sido medidas la pendiente, el radio y el ancho de la plataforma vial en 10 curvas en "U"; la información se halla georreferenciada y se comparan los datos calculados según el Reglamento Nacional de Construcción de Vías (MTC, 2009) con la información obtenida en campo, tal como se detalla en la Tabla 2.

Se colige que, en un $100 \%$, el peralte de las curvas difiere a los datos calculados; por lo tanto, todas las curvas presentan un peralte inadecuado, usualmente menor al peralte obtenido. Las curvas no presentan una adecuada señalización preventiva ni informativa respecto a la velocidad de acceso a la curva. Los primeros cuatro peraltes medidos tienen un porcentaje superior al optimo; seis peraltes se hallan muy por debajo de lo óptimo, hecho que genera que los vehículos que ingresan a una velocidad mayor a lo recomendado, podrían ser impulsados por la fuerza centrífuga, provocando accidentes.

Es pertinente considerar que el peralte que debe tener una carretera en una curva determinada a la cual se debe conducir a una velocidad estipulada de acuerdo al tipo de la carretera es uno de los parámetros a ser considerados en su construcción, de allí lo relevante que es tener un fundamento estable en lo que se refiere a estos tópicos para así evitar accidentes. Cuando un vehículo recorre una vía en pendiente cuyo perfil longitudinal presenta una curvatura importante, como las evaluadas en el tramo carretero, queda sometida a una aceleración vertical que puede modificar las condiciones de estabilidad y afectar considerablemente el confort de los pasajeros. Para evitar discontinuidades en las aceleraciones aplicadas al vehículo al recorrer éste en la curva vertical, es conveniente hacer que la aceleración vertical aparezca gradualmente.

Esto se logra mediante una transición de la curvatura de perfil longitudinal, introduciendo una curva cuya razón de variación de pendiente sea constante. Por otra parte, la condición de movimiento que se considera óptima para un vehículo en un alineamiento vertical es aquello que corresponde a un movimiento cuya componente horizontal de la velocidad es constante, esto reside en las características del peralte que en el caso de las 10 curvas analizadas no corresponden a lo planteado en la normatividad nacional.

Dentro del marco del proyecto global de infraestructura vial, es el diseño geométrico la fase más predominante, pues, es a partir de este que se establecen las características geométricas representadas tridimensionalmente, de modo que resulte funcional, segura, cómoda, estética, económica y compatible con el ambiente (Cárdenas, 2015) 


\section{Análisis de los Resultados en Taludes}

El manejo de taludes tiene enorme importancia en la gestión de vías, evitan deslizamientos, hundimientos, desprendimientos de rocas y sedimentos con el consiguiente deterioro de la plataforma y cunetas; consecuentemente, un talud con pendiente adecuada servirá de protección y evitará gastos en mantenimiento.

La información de la Tabla 3, y corroborado con las hojas de campo, especificadas en las Figuras 3 y 4, evidencia que no existe manejo adecuado de taludes, pues muestran pendientes superiores a las recomendadas para suelos, sedimentos y rocas inestables, fracturadas y con alto grado de cizallamiento, generando alto costo en mantenimiento de la vía, cunetas y en la transitabilidad vehicular. Todas las pendientes son superiores a $60^{\circ}$; más del $72 \%$ de los taludes presentan pendientes superiores a $70^{\circ}$; considerando la naturaleza de las rocas y sedimentos frágiles, falta de cobertura vegetal y ausencia de cunetas de coronación, constituyen acciones de alto riesgo que generan deterioro en la vía con el consiguiente gasto en mantenimiento.

La estabilidad de los taludes y laderas se encuentran condicionadas por diversos factores, por lo que su estudio es fundamental para evitar consecuencias serias para las obras viales; las vías de comunicación son vulnerables a los diferentes deslizamientos que pudieran ocurrir a lo largo de su historia, siendo de igual relevancia los posibles siniestros de vehículos. En base a esto, los estudios geotécnicos conforman un nuevo paradigma en la seguridad vial, puesto que permiten prevenir, mitigar o corregir movimientos de masas que afecten las vías de comunicación. En el ámbito de estudio se ha verificado y medido la pendiente de los taludes y evaluado la naturaleza geológica y se ha determinado el siguiente árbol de problemas mostrado en la figura 5.

\section{Figura 5.}

Árbol de problemas en inestabilidad de taludes.

De la figura 5 se colige que del deficiente tratamiento de suelos y vegetación se pueden generar mayores accidentes de tránsito, una mayor incidencia de deslizamientos y asentamientos rocosos y el avance progresivo del diaclasamiento y cizallamiento de las rocas y sedimentos.

\section{Identificación y Evaluación de Impactos Ambientales}

Dentro del Estudio de Impacto Ambiental se desarrollan procesos que conlleven a cumplir fines, mediante recopilación de datos, análisis, evaluación e interpretación de posibles factores que causen impactos a los componentes del ambiente, para ello se utilizaron métodos específicos para la identificación de impactos de forma cualitativa o cuantitativa.

A lo largo del tramo se identificaron y evaluaron actividades que causan problemas de inestabilidad en la plataforma vial, deslizamiento de rocas y sedimentos, relleno de las cunetas con rocas y sedimentos, reducción de la plataforma vial por erosión e impactos a la diversidad biológica. 


\section{Tipología de Impactos}

\section{Tabla 4}

Evidencia las actividades y los tipos de impactos generados.

De las doce actividades analizadas en la etapa de funcionamiento, diez son desfavorables y solo dos se califican como favorable y muy favorable. Es imprescindible introducir acciones correctivas para mantener en óptimas condiciones la operación de la vía. Por la valoración de la calidad ambiental, que es calificada como positiva y negativa, diez acciones son negativas y dos son positivas, siendo afectados los recursos naturales y componentes de la biodiversidad.

Referente al grado de destrucción, ocho de las doce acciones se califican entre alto y muy alto; es decir, la intensidad del impacto es fuerte y, considerando la persistencia de los impactos, ocho son de carácter permanente y cuatro temporales. Respecto a la capacidad de recuperación de impactos, tres son reversibles, siete son mitigables y dos son recuperables. Estos resultados evidencian que todas las acciones que generan impactos pueden ser revertidas si se introducen acciones correctivas.

Finalmente, considerando la introducción de medidas correctivas, cuatro de las acciones son severas, tres críticas, cinco moderados; por lo tanto, las acciones severas y críticas son las que deberían tener prioridad en su manejo. La interacción entre las actividades, durante el funcionamiento de la vía y los factores ambientales, se muestra mediante la matriz causa/efecto en la etapa de operación, tal como lo evidencia la Tabla 5.

Existen acciones que generan impactos muy desfavorables en los factores ambientales; análogamente existen factores ambientales impactados. La matriz debe ser interpretada horizontalmente para observar las variables ambientales impactadas, y verticalmente para analizar las acciones ejecutadas en la vía que impactan a los factores ambientales. Las acciones que mayor impacto generan sobre factores ambientales son el no manejo de micro-cuencas y la falta de obras físicas para el manejo de taludes; ambas alcanzan una suma total de -09, impactando negativamente a la mayoría de factores ambientales. Por estas acciones se ve afectado el drenaje y la inestabilidad de taludes provoca erosión, con el consiguiente deterioro de cunetas, pontones y carpeta asfáltica.

La suma total de la matriz arroja una cifra negativa de -11, implicando que las interacciones planteadas en la matriz generan impactos negativos que deben ser revertidos y/o mitigados para evitar el deterioro ambiental. La matriz aplicada muestra como resultado dos acciones positivas: el incremento del tráfico vehicular y el ciclismo de montaña, con resultados positivos (03 y 06 , respectivamente). La variable socio-económica y sus componentes, exceptuando la generación de residuos sólidos, arroja resultado positivo, evidenciando que el funcionamiento de la carretera tiene efectos positivos. 


\section{Matriz de Importancia}

La metodología matricial de Conesa (2010), busca determinar, de manera numérica, la importancia de los impactos ambientales, dependiendo la misma de la caracterización de cada impacto a través de 11 atributos. La importancia la determina a través de la Fórmula 3:

$$
\mathrm{I}= \pm(3 \mathrm{IN}+3 \mathrm{EX}+\mathrm{MO}+\mathrm{PE}+\mathrm{RV}++\mathrm{SI}+\mathrm{AC}+\mathrm{EF}+\mathrm{PR}+\mathrm{MC}) .
$$

\section{Fórmula 3}

La matriz de importancia, indicada en la Tabla 6, constituye un método analítico mediante el cual se le asigna la importancia (I) a cada impacto ambiental identificado en la etapa de operación de la carretera.

Se colige que los efectos más relevantes en esta etapa son sobre los riesgos que los accidentes podrían generar sobre personas, animales u objetos y el incremento en el tránsito vehicular, con el consecuente aumento en las emisiones de hidrocarburos, gases y material particulado; igualmente, la contaminación de aguas superficiales y modificación del paisaje por acciones antrópicas; los efectos positivos, como la revegetación de taludes y la generación de fuentes de trabajo para el mantenimiento de la vía. Existen, además, impactos negativos, calificados como puntuales y pasajeros (olores y ruidos).

\section{Descripción de los Principales Impactos Ambientales}

Las hojas de campo, señaladas en las Figuras 3 y 4 recogen observaciones, evalúan posibles causas que generan el problema y proponen alternativas viables. Consta de la ubicación, descripción del problema, identificación y evaluación de los sectores críticos existentes y propone solución. A guisa de ejemplos, se incluyen dos hojas de campo.

\section{Hoja de Campo $\mathrm{N}^{\circ} 4$ (Figura 3)}

Nombre del tramo: Abra Málaga-Alfamayo

Progresiva: Km. $140+134$

Descripción del Problema. Desprendimiento y deslizamiento de material rocoso y sedimentos por falta de vegetación y pendiente de $67^{\circ}$, provoca accidentes de tránsito.

Causas del Problema. Escaso recubrimiento de vegetación, pendiente ubicada al comienzo de la curva en "C" y falta de señalización. 
Soluciones Planteadas. Construir gaviones de piedra de hasta 12 metros de altura y recubrir con vegetación nativa de la zona (Chusquea spp.; Polylepis sp; Mircyne sp.) e instalar señalización informativa.

\section{Hoja de Campo $N^{\circ} 14$ (Figura 4)}

Nombre del tramo: Abra Málaga-Alfamayo

Progresiva: $\mathrm{Km} 158+700$

Descripción del Problema. Deslizamiento de material rocoso y sedimentos; cunetas y carril obstruidos, afloramiento de manante; inadecuada señalización.

Causas del Problema. Pendiente alta de $79.5^{\circ}, 150$ metros de largo y aguas superficiales discurriendo por la pendiente, inadecuada señalización y falta de vegetación.

Soluciones planteadas. Construcción de cunetas de coronación y terraplenes de cinco metros de altura, recubrimiento con vegetación nativa (Chusquea spp; Cecropia sp. Coriaria ruscifolia L.), colocación de señalización informativa y preventiva y, el manante derivarlo mediante un conducto evitando que discurra por la ladera generando erosión y arrastre de sólidos a la vía.

En resumen, en la etapa de operación y mantenimiento de la vía en el tramo estudiado se analizaron los siguientes impactos derivados de las acciones inherentes a esta etapa de funcionamiento y se sugieren medidas de mitigación en las etapas de operación y mantenimiento, tal como lo señala la Tabla 7.

\section{Medidas Correctivas}

Permiten minimizar, controlar y dotar a una carretera en operación de mejores características técnicas. En este tramo de la carretera se evidenciaron impactos para los cuales se sugiere:

a. Peralte adecuado. Otorga estabilidad al vehículo al ingresar a una curva. Los datos obtenidos indican que el peralte no cuenta con el ángulo adecuado, sugiriéndose:

- Implementar señalización informativa y preventiva.

- Mejorar y reajustar la pendiente del peralte, considerando el radio de la curva y el ancho de la vía, como especifica el Reglamento Nacional de gestión de infraestructura Vial (MTC, 2008a).

- Mejorar y reajustar el radio de la curva.

b. Manejo de taludes. El inadecuado manejo de taludes con una inclinación y pendiente fuertes, con rocas y sedimentos frágiles, con ausencia de vegetación, empeora las condiciones de estabilidad. Considerando la alta precipitación en la zona, genera deslizamientos con costos de mantenimiento de cunetas, pontones y 
plataforma de rodadura. Se determinaron diecisiete sectores que generan riesgos e impactos severos. Se plantea medidas correctivas para cada sector observado de acuerdo a la Tabla 8.

c. Señalización vial. Es de vital importancia, forma parte del mantenimiento, dada su incidencia en la seguridad de la vía; es un elemento crítico que requiere una vigilancia y reposición constantes. El objetivo es indicar los riesgos, prohibiciones $\mathrm{u}$ obligaciones existentes en un emplazamiento y momento dados, mediante un conjunto de estímulos visuales que ayuden a disminuir los riesgos.

d. Manejo de microcuencas. Han sido analizadas 15 microcuencas que forman parte de la subcuenca del río Lucumayo. Estos cursos de agua son cortados por la vía; no evidencian un manejo, no poseen sistemas para controlar la presión hídrica durante la época de lluvias y tampoco existe reforestación para evitar erosión. La precipitación pluvial es alta y los riachos se incrementan súbitamente. Se sugiere:

- Mantener con vegetación nativa ambas márgenes de los riachos para evitar la erosión y arrastre de sólidos; ello implica reforestación.

- Construir banquetas en el cauce de los riachos; estos actuarán como disipadores de presión y velocidad.

- Limpiar y mantener los pontones antes y después de la temporada de lluvias.

- Mantener las cunetas laterales, construir cunetas de coronación y revegetar con especies nativas que cumplan un papel de retención del agua.

e. Revegetación. Cumple función de protección de los suelos evitando:

- Arrastre de sedimentos por acción de la lluvia. La vegetación amortigua el impacto de las gotas sobre el material suelto y reduce la velocidad de escorrentía.

- La disgregación del suelo por la acción del agua. Las raíces superficiales y profundas mantienen la cohesión del terreno.

- Las plantas por evapotranspiración extraen agua del suelo.

Las especificaciones generales para la revegetación son:

- En la revegetación considerar el uso de especies herbáceas y/o poaceas locales.

- La revegetación en taludes debe ser de tal forma que se asemeje a la distribución de las formaciones naturales.

- Es recomendable el uso de especies locales como Chusquea spp., Coriaria ruscifolia, Cecropia sp, Bocconia frutescens L., Myrsine sp., Dodonea viscosa L.

f. Manejo y protección de la biodiversidad. La cobertura vegetal debe ser similar a la original, porque incide directamente sobre la fauna que allí habita. Sin embargo, se presentan zonas donde, por las limitaciones de clima, suelo y agua, se precisa el establecimiento de especies más resistentes, que cumplan una función específica, como el control de erosión y estabilización. Se deberá considerar:

- El ecosistema e identificar las especies vegetales adecuadas. 
- Los taludes, deslizamientos y erosión que afectan el paisaje deben ser tratados con especies de la zona.

La carretera se constituye en barrera física, fragmentando el bosque montano. Se debe corregir mediante la construcción de pases para mamíferos, reptiles y anfibios. Se sugiere:

- Forestar con especies arbóreas nativas que posibiliten el anidamiento de aves.

- Construir pases para mamíferos que se movilizan de una zona a otra.

- Adecuar los pontones para la circulación de especies reptantes.

Las metodologías empleadas para medir los impactos en el entorno, evidencian tanto los impactos negativos en esta etapa de operación, así como los impactos positivos; la tabla 9, muestra un resumen comparativo de los resultados de los tres métodos.

\section{Tabla 9.}

Impactos positivos y negativos según matriz utilizada para medir impactos ambientales del tramo de estudio.

Los tres métodos utilizados para evaluar los impactos ambientales del tramo carretero en la etapa de funcionamiento, evidencian que 30 variables ambientales son impactadas negativamente $(71 \%)$ y 12 variables ocasionan impactos positivos (29\%). La matriz de tipología de impactos determina que el $83 \%$ de las variables medidas son impactadas negativamente; no obstante, si se introdujeran las acciones correctivas, especificadas en el Plan de Manejo Ambiental, en la etapa de funcionamiento, muchos de estos impactos no se producirían o sus efectos serían reversibles.

\section{Discusión}

Gordon (2009) plantea que, en el diseño de vías, se considere no sólo el efecto de las precipitaciones registradas sino también el de las estimadas a futuro. Nuestros estudios en campo, además, añade que es pertinente asegurar un dimensionamiento adecuado de las obras y las necesidades de mantenimiento posterior, junto a la correcta aplicación de las medidas necesarias para minimizar los impactos ambientales en la etapa de operación.

Kraemer et al. (2003), referido a la durabilidad de las carreteras, plantea que es pertinente considerar el cambio climático en su diseño, construcción y mantenimiento. Los trabajos de campo nos permiten especificar que el punto de partida para mejorar la resiliencia de la carretera es preciso tener en cuenta las particularidades de cada territorio, ya que las condiciones y previsiones climáticas son muy diferentes de una zona a otra, donde pueden existir escenarios climáticamente distintos. El conocimiento de la 
singularidad climática del territorio sobre el que se está trabajando es una de las claves para identificar las soluciones técnicas que pudieran resultar más efectivas en función del emplazamiento, la vulnerabilidad y las amenazas existentes, tal como ocurre en la zona de estudio.

Respecto del peralte en carreteras, el MTC (2008b) señala que la finalidad del peralte es contrarrestar la acción de la fuerza centrífuga, las curvas horizontales deben ser peraltadas y que el peralte máximo tendrá como valor máximo normal $8 \%$, y que para velocidades directrices iguales o mayores a $40 \mathrm{Km} / \mathrm{h}$ tendrá como valor excepcional $10 \%$. En casos extremos podría justificarse un peralte máximo de alrededor de $12 \%$, en cuyo caso deberá considerarse un incremento en el ancho de cada carril para evitar que los camiones que circulan en un sentido invadan el carril del sentido contrario. Los trabajos de campo demuestran que ninguno de los peraltes evaluados se ajusta a lo señalado por el MTC (2008b).

MTC (2010a), al hacer el estudio de la carretera Ayacucho-Abancay, especifica que existe un tratamiento adecuado de los taludes; en cambio, en el tramo estudiado, no existe un manejo adecuado de taludes, pues estos muestran pendientes superiores a los recomendados para suelos, sedimentos y rocas inestables, fracturadas y con alto grado de cizallamiento.

Hob Consultores S.A. (2011) y Walsh Perú (2006) plantean que una carretera es una barrera física; coincidimos con esta afirmación, además, incluimos propuestas para resolver este problema estructural, sugerimos la construcción de pases para mamíferos que se movilizan de una zona a otra y adecuar los pontones para la circulación de especies reptantes y anfibios.

Dourojeanni (2006) sostiene que, en la carretera interoceánica, los impactos ambientales más probables, en un horizonte de más de 10 años, incluyen: incremento de la deforestación, degradación de bosques naturales, invasión de áreas protegidas, mayor incidencia de incendios, expansión del cultivo de coca, explotación anárquica de oro, degradación del ambiente urbano, pérdida de biodiversidad, incremento de caza y pesca, reducción de la calidad de los servicios ambientales, en especial del recurso hídrico. Nuestros estudios en el tramo carretero no sólo son coincidentes con estas conclusiones, sino que la biodiversidad ya se ve afectada y la no implementación del Plan de Manejo Ambiental genera consecuencias sociales y económicas.

Fernández (2009) especifica que la actividad económica que promueve una carretera, particularmente en la amazonía, posee debilidades y fortalezas; lo interesante es evidenciar los factores que impiden o favorecen el desarrollo de actividades económicas sostenibles y de conservación. Si bien es cierto que la carretera Cusco-Quillabamba dinamiza la economía de los pueblos, nuestras observaciones permiten colegir que también puede significar deterioro e impactos ambientales que deben ser corregidos.

La evaluación biológica desarrollada por Walsh Perú (2007) en el tramo 2 de la carretera interoceánica, señala la fragilidad de la fauna y flora y su escasa resiliencia a la construcción de la carretera. Nuestros estudios ratifican esa percepción; además, brindan sugerencias para mitigar los impactos.

Sacher (2013) concluye que, en carreteras en operación existen posibilidades de contaminación del agua, aire, así como amenazas a la flora o la fauna, y efectos severos 
para la salud de las poblaciones de los alrededores. Nuestro trabajo de campo y la aplicación de las metodologías de evaluación, señalan que, de las 42 variables ambientales identificadas, más del 80\% sufren impactos negativos debido a la no aplicación del plan de manejo ambiental.

Hipólito (2020), concluye que una de las grandes deficiencias encontradas en la construcción de carreteras es el radio de giro y que las curvas no cuentan con sobre anchos calculados ni ejecutados; por lo tanto, no se tiene un tránsito fluido y continuo en la vía. En efecto, en el tramo estudiado, todas las curvas tienen un mal diseño referido a los peraltes, posibilitando que los vehículos al ingresar a una curva invadan el carril contrario o podrían ser expulsados por la fuerza centrífuga, generando accidentes.

Gómez, et al, 2017, señalan que los accidentes ocurridos en la vía ManizalesNeira, se generan por diversos motivos entre ellos la infraestructura inadecuada que incluye la señalización deficiente, pavimentos deteriorados e incumplimiento del Manual Colombiano de Diseño Geométrico de Carreteras de 2008. En el caso del tramo carretero de $29 \mathrm{Km}$ estudiado, la incidencia de accidentes se debe a un inadecuado peralte, taludes inadecuadamente diseñados y con escaso mantenimiento, falta de señalización y ciertamente no aplicación del plan de manejo ambiental en la etapa de operación.

El Consorcio GEGOCONSUL T-CPA (2008), en el Estudio de Impacto Ambiental de la carretera Panamericana Sur: Puente Montalvo-Puente Camiara, los impactos son: Disminución de la Calidad del Aire, emisiones sonoras, alteración del paisaje, probable contaminación de suelos, generación de empleo; nuestros estudios en el tramo carretero, señalan que además de los indicados por el Consorcio, los impactos afectan a la flora y fauna, puesto que la carretera atraviesa por ecosistemas frágiles ricos en diversidad biológica.

El Consorcio vial Hualgayoc (2010), realizó un estudio de impacto socio ambiental de la rehabilitación y mejoramiento de la carretera Chongoyape-CochabambaCajamarca tramo Bambamarca-Hualgayoc, determinándo los siguientes impactos: Pérdida de la calidad del aire por material particulado, gases y ruido y perturbación de la fauna silvestre. Nuestros estudios no sólo son coincidentes con estos resultados, sino que sugieren alternativas para disminuir los impactos generados y proponen la aplicación del plan de manejo ambiental aprobado.

Es pertinente especificar que el Perú y la región Cusco seguirán construyendo carreteras debido a que constituyen infraestructuras de desarrollo; sin embargo, se debe poner en ejecución el plan de manejo ambiental aprobado en los estudios de impacto ambiental y en dicho plan debe de estar contemplado las características locales por donde atraviesa la vía, con especificidad de las rutas migratorias para la fauna, los ecosistemas que contienen recursos vegetales con escasa resiliencia, especialmente la vegetación nativa y endémica; asimismo, es necesario se contemple la revegetación con especies de rápido desarrollo y que recuperen los ecosistemas degradados y que además, se incluya la variable cambio climático por tener efectos locales y, finalmente el Ministerio de Transportes y Comunicaciones efectúe el seguimiento y fiscalización en la etapa de operación y mantenimiento de la carretera. 


\section{Conclusiones}

En la Zona de Vida bosque húmedo montano sub-tropical existen especies nativas que requieren ser conservadas: Juglans neotropica Diels "nogal", Escallonia resinosa (Ruiz \& Pav.) Pers. "chachacomo", Cinchona pubescens Vahl "cascarilla", Podocarpus glomeratus D. Don "intimpa", Nectandra herrerae O.C. Schmidt "laurel”, Hesperomeles lanuginosa Ruiz \& Pav. ex Hook. "mayu manzana", Myrsine pellucida (Ruiz \& Pav.) Spreng. "chalanque", Myrica pubescens Humb. \& Bonpl. ex Willd. "laurel de puna", Vallea stipularis L. f. "chiqllurmay" y Myrcianthes oreophila (Diels) McVaugh "unka"; son maderables y forman una cobertura vegetal densa y un sotobosque importante, retienen humedad, controlan erosión y servicios ambientales hídricos.

La fragmentación del hábitat generada por la carretera y el consecuente aislamiento de poblaciones de la fauna silvestre es el impacto más significativo, puesto que el efecto barrera y el efecto de borde afectan la disponibilidad de alimento y el potencial reproductivo de las especies. El número de animales muertos por atropellamiento reportados en algunos estudios es significativamente alto y puede representar un riesgo para las especies en estado de amenaza.

El Plan de Manejo Ambiental (PMA) del EIA durante la etapa de construcción propone medidas de prevención, atenuación, mitigación y restauración; estas medidas no han sido implementadas afectando a mamíferos, reptiles y anfibios, pues, no existen pases en la vía para la movilidad de estos organismos. Debido al incumplimiento de las acciones sugeridas en el PMA, entre 2010 y 2015 se verificaron 90 acciones de emergencia identificadas, generando perjuicios sociales, económicos y ambientales con alto costo en la vialidad y sus funciones.

Más del $70 \%$ de los taludes presentan pendientes superiores a $70^{\circ}$; considerando la naturaleza de las rocas con alto nivel de cizallamiento, falta de cobertura vegetal y cunetas de coronación, provoca deslizamientos y derrumbes con deterioro de cunetas y plataforma de rodadura. Se plantea: construcción de muros de contención, gaviones, terraplenes, cunetas de coronación y revegetación.

Los impactos ambientales en la etapa de funcionamiento se hallan catalogados como desfavorables, de intensidad muy alta, severos, críticos; sin embargo, reversibles y mitigables si se introducen acciones correctivas.

El efecto barrera de la vía, en la etapa de funcionamiento, afecta directa y permanentemente al oso de anteojos (Tremarctos ornatus F.G. Cuvier, 1825), puma (Puma concolor Linnaeus, 1771), zorro andino (Dusicyum culpaeus Molina, 1782), venado colibanca (Odocoileus virginianus Zimmermann, 1780) y reptiles, anfibios e insectos reptantes, puesto que no se han construidos pases.

La especie con mejores características para la revegetación de taludes es la Chusquea spp.; es nativa, posee raíces anastomosadas que retienen la erosión, forma suelos, posibilita el anidamiento de aves y es de fácil manejo. La protección de la biodiversidad es nula; se plantea instalación de pases para la movilización de mamíferos y mantenimiento de pontones para circulación de reptiles y anfibios.

El caudal de los riachos en temporada de lluvias se incrementa sustancialmente, siendo necesaria la implementación de cunetas de coronación, limpieza de cunetas de 
drenaje, pontones e instalación de banquetas en el cauce de los riachos. No existen sistemas para disipar la carga de presión hidráulica durante la época de lluvias.

El $100 \%$ de los peraltes de las curvas no cuenta con el adecuado porcentaje de inclinación, generando la inestabilidad del vehículo al ingresar a la curva; los vehículos invaden el carril contrario provocando accidentes. Se plantea reajustar el peralte, el radio de la curva y la señalización informativa.

Mediante Resolución $\mathrm{N}^{\circ}$ 160-2016-MINAM se dio por culminada el proceso de transferencia de funciones del sub sector transportes al Servicio Nacional de Certificación Ambiental para las Inversiones Sostenibles-SENACE, por lo que desde el 14 de julio del 2016 el SENACE ha asumido la función de revisar y aprobar los Estudios de Impacto Ambiental Detallados, las respectivas actualizaciones, modificaciones, informes técnicos sustentatorios, solicitudes de clasificación y aprobación de Términos de Referencia, acompañamiento en la elaboración de Línea Base, Plan de Participación Ciudadana, Plan de manejo ambiental y demás actos o procedimientos vinculados a las acciones antes señaladas. En la sección correspondiente a Certificación Ambiental para el sector transporte se precisa las delimitaciones de competencias correspondientes a la Dirección General Asuntos Socio-Ambientales-DGASA del MTC y el SENACE; consecuentemente, se encuentra dentro de las competencias de SENACE el control, seguimiento, monitoreo y fiscalización de la aplicación del Plan de manejo ambiental en la etapa de operación en el tramo carretero en estudio.

\section{Agradecimientos}

Expresamos nuestro público reconocimiento a la Ing. Geóloga Magali Violeta García Mujica por su apoyo en los trabajos de campo y a la Blgo. Modesta Esther Álvarez Moscoso por su apoyo en la identificación de las especies de flora y fauna.

\section{Declaración de Conflicto de Intereses}

Los autores declaran no tener conflictos de interés de ninguna índole que puedan influir en el desarrollo de la presente investigación. 


\section{Referencias}

Ángel E. (2010). Métodos cuantitativos para la toma de decisiones ambientales. Medellín: Universidad Nacional de Colombia. Todográficas Ltda. Colombia.

Arboleda J. (2008). Manual de evaluación de impacto ambiental de proyectos, obras o actividades. Medellín / Colombia.

BID (Banco Interamericano de Desarrollo). (1997). Evaluación ambiental para el sector transporte. Guía para la gestión de estudios y programas de mitigación ambiental. Washington DC.

BID (Banco Interamericano de Desarrollo). (2015). Guía para evaluar y gestionar los impactos y riesgos para la biodiversidad en los proyectos respaldados por el Banco Interamericano de Desarrollo. Nota Técnica $N^{\circ} I D B-T N-932$. Washington.

Bishop, A.W \& Henkel, D.J. (1962). The measurement of soil properties in the triaxial test. Edit Arnold, Londres.

CAF (Corporación Andina de Fomento). (2018). Guía de Buenas Prácticas para la Adaptación de las Carreteras al Clima. Caracas.

Canter L.W. (1998). Manual de Evaluación de Impacto Ambiental, Técnicas para la elaboración de los Estudios de Impacto. McGRAW-HILL. Madrid.

Cárdenas, J. (2015). Diseño Geométrico de Carreteras. Primera Edición. Lima: Macro EIRL.

Conesa V. (1995). Guía metodológica para la evaluación del impacto ambiental. Ediciones Mundi-Prensa. Madrid.

Conesa V. (2010). Guía Metodológica para la Evaluación del Impacto Ambiental. $4^{\mathrm{a}}$ Edición (revisada y ampliada). Ediciones Mundi-Prensa. Madrid.

Consorcio GEGOCONSUL T - CPA. (2008). Estudio Definitivo para el Mantenimiento Periódico de la Carretera Panamericana Sur Tramo: Puente Montalvo - Puente Camiara. Lima.

Consorcio vial Hualgayoc. (2010). Estudio de impacto socio ambiental de la rehabilitación y mejoramiento de la carretera Chongoyape-Cajamarca, tramo BambamarcaHualgayoc. Lima.

Constanza, Robert; d'Arge, Ralph; de Groot, Rudolf; Farber, Sthepen; de Grasso, Mónica; Hannon, Bruce. (1997). The Value of the World's Ecosystem Services and Natural Capital. Nature; 1997; p. 387. 37. Asamblea General de las Naciones Unidas. $61^{\text {a }}$ sesión de la Asamblea General de las Naciones Unidas. Sitio en internet. Recuperado de: http://www.un.org/es/comun/docs/?symbol=A/RES/61/203.

Dourojeanni M. (2006). Estudio de caso sobre la carretera Interoceánica en la amazonia sur del Perú. Bank Information Centre [Financiación]. Ediciones Mundi-Prensa. Madrid. Recuperado de: http://siar.minam.gob.pe/puno/sites/default/files/ archivos/public/docs/437.pdf. 
Dueñas A., Ramírez, V. Defilippi, M. (2012). Tópicos de ingeniería y gestión ambiental. $P U C P$. Publicaciones para la docencia. Lima.

Espinoza, G.; Pisani, P. \&; Ulloa, M. (2000). Metodología Integrada para la Revisión de Evaluación de Impacto Ambiental (MIREIA). Centro de Estudios para el Desarrollo. Santiago, Chile. p.215.

Fernández Felipe-Morales L. (2009). Diagnóstico de los impactos integrados de la carretera Interoceánica Sur en la Región de Madre de Dios. Wildlife Conservation Society. Lima. Recuperado de: https://biblioteca.spda.org.pe/biblioteca/ mcatalogo/_data/20200124203342_Fernandez\%20Felipe_Lourdes.pdf

Forman, R. T. \& Alexander, L. E. (1998). Roads and their major ecological effects. En: Annual Review of Ecology and Systematics 29: 207-231.

Gallopín, G. C. (1997). Indicators and Their Use: Information for Decision-making. Part One-Introduction. pp.13-27 en: Moldan, B. and S. Bilharz (Eds.). Sustainability Indicators. A Report on the Project on Indicators of Sustainable Development. SCOPE 58. Wiley, Chichester.

Garmendia, A.; Salvador A.; Crespo, C.; Garmendia, L. (2005). Evaluación de Impacto Ambiental. Madrid: Pearson educación, p. 75. ISBN: 84-20-4398-5.

Gómez, M. C.; Escobar, D. A.; Urazán, C. F. (2017). Relación técnica entre seguridad vial, accidentalidad y lineamientos de diseño geométrico. Estudio de caso: Vía Manizales - Neira. Bogotá, Colombia.

Goosem, M. (2002). Effects of tropical rainforest roads on small mammals: fragmentation, edge effects and traffic disturbance. En: Wildlife Research 29: 277-289.

Gordon K. (2009). Ingeniería de Caminos Rurales. Guía de Campo para las Mejores Prácticas de Administración de Caminos Rurales. California / USA.

Hernández Sampieri, R. et al. (1991). Metodología de la investigación. México: Mc Graw Hill.

Hernández Roberto et al. (2013). Metodología de la investigación. Recuperado de: www. upsin.edu.mx/mec/digital/metod_invest.pdf

Hipólito Guerrero, K. F. (2020). Propuesta de diseño geométrico en planta de la carretera Huayñia-Yauyos progresiva $\mathrm{km} 2+300 \mathrm{a} \mathrm{km} \mathrm{3+300} \mathrm{en} \mathrm{el} \mathrm{Centro} \mathrm{Poblado} \mathrm{Yauyos,}$ de la Provincia de Yauyos 2020. Tesis, Universidad César Vallejo. Lima.

Hob Consultores S.A. (2011). Estudio Definitivo del Proyecto de Mejoramiento de la Carretera Satipo - Mazamari - Dv. Pangoa - Puerto Ocopa. Informe final. Informe $\mathrm{N}^{\circ}$ 04-Volumen I. Memoria descriptiva y estudios básicos Anexo F, Tomo 4/5. Estudio de estructuras y obras de arte. Componente Ingeniería. Ministerio de Transportes y Comunicaciones. Lima / Perú.

Kattan, G. (2002). Fragmentación: patrones y mecanismos de extinción de especies. En: Guariguata M. y G. Kattan (eds). Ecología y conservación de bosques neotropicales. Ediciones LUR, Cartago. 
Keller G., Bauer G. \& Aldana M. (1995). Caminos Rurales con Impactos Mínimos. Un Manual de Capacitación con Énfasis sobre Planificación Ambiental, Drenajes, Estabilización de Taludes y Control de Erosión. USAID, US Forest Service, Ministerio de Comunicaciones, Transporte y Obras Públicas de Guatemala. Guatemala. recuperado de: http://repositorio.mopt.go.cr:8080/ xmlui/123456789/3696.

Kraemer C., Pardillo J. M., Rocci S., Romana M. G., Sánchez V. \& del Val, M.A. (2003). Ingeniería de Carreteras, Volumen I. Primera edición. McGraw-Hill \& Interamericana de España. Madrid.

Liberman, M; Salm, H; Paiva, B. (2000). Manual ambiental para la construcción de carreteras. Los estudios de evaluación de impacto ambiental de carreteras en Bolivia. La Paz, Bolivia. 279 p.

MTC (Ministerio de Transporte y Comunicación). (2005 ). Resumen Ejecutivo del informe Actualización del Estudio Definitivo de Ingeniería para la Rehabilitación y Mejoramiento de la Carretera Ollantaytambo - Quillabamba - Kiteni. MTCDRTC. Cusco / Perú.

MTC (Ministerio de Transporte y Comunicaciones). (2005b). Manual de Gestión Socio Ambiental para Proyectos Viales Departamentales. MTC\DGASA. Lima / Perú. https://portal.mtc.gob.pe/transportes/socioambientales/documentos/MGSAPVD. pdf.

MTC (Ministerio de Transporte y Comunicación). (2005c). RD N068-2005-MTC/16: Se Resuelve aprobar el Manual de Gestión Socio Ambiental para Proyectos Viales Departamentales. del 22 de noviembre de 2005. MTC $\backslash$ DGASA. Lima / Perú. Recuperado de: https://cdn.www.gob.pe/uploads/document/file/390331/ RD Nro 068-2005-MTC-16.pdf.

MTC (Ministerio de Transporte y Comunicaciones). (2005d). Manual Técnico de Mantenimiento Periódico para la Red Vial Departamental no Pavimentada. PROVIAS Departamental. Programa de Caminos Departamentales. Aprobado por la Resolución Directoral N 015-2006-MTC/14 de 22 de marzo de 2006. Lima / Perú. Recuperado de: http://www.sutran.gob.pe/wp-content/uploads/2015/08/ manualmatenimiento periodico para la red vial departamental no pavimentada.pdf.

MTC (Ministerio de Transporte y Comunicación). (2005e). Actualización del Estudio Definitivo de Ingeniería para la Rehabilitación y Mejoramiento de la Carretera Ollantaytambo - Quillabamba - Kiteni, Informe Final. Cusco: DRTC. Perú.

MTC (Ministerio de Transporte y Comunicación). (2006). Estudio de Impacto Ambiental Construcción y Mejoramiento de la Carretera Cusco - Quillabamba; Tramo: Alfamayo - Chaullay - Quillabamba. Informe Final - Estudio de Impacto Ambiental. Consorcio Quillabamba y DRTC/MTC. Cusco / Perú. Recuperado de: http://gis.proviasnac.gob.pe/expedientes/2012/Saldo\%20alfamayo/CD1/10.Impacto \%20Ambiental/INF.FINAL \%20EIA/INFORME \%20FINAL.EIA \%20 S\%20R\%20Jul2009.doc. 
MTC (Ministerio de Transporte y Comunicación). (2007). Decreto Supremo 017-2007MTC: Aprueban Reglamento de Jerarquización Vial. El Peruano, 25(9846): 345964-345970. 26 de mayo de 2007. Lima / Perú. Recuperado de: https://epdoc2. elperuano.pe/EpPo/Descarga.asp?Referencias=TkwyMDA3MDUyNg==.

MTC (Ministerio de Transporte y Comunicación). (2008 $)$. Decreto Supremo 0342008-MTC: Reglamento Nacional de Gestión de Infraestructura Vial. El Peruano, 25(10400): 382163-382170. 25 de octubre de 2008. Lima I Perú. Recuperado de: https://epdoc2.elperuano.pe/EpPo/Descarga. asp?Referencias=TkwyMDA4MTAyNQ==.https://portal.mtc.gob.pe/transportes/ caminos/normas carreteras/documentos/otras/DS\%20N\%C2\%B0\%200342008-MTC\%20Reglamento\%20Nacional $\% 20 \mathrm{de} \% 20 \mathrm{Gesti} \% \mathrm{C} 3 \% \mathrm{~B} 3 \mathrm{n} \% 20$ Infraestructura\%20Vial.pdf.

MTC (Ministerio de Transporte y Comunicación). (2008b). Manual para el Diseño de Carreteras Pavimentadas de bajo volumen de tránsito. MTC-DRTC. Lima / Perú. Aprobado por Resolución Ministerial No 303-2008-MTC/02. Recuperado de: $\quad$ http://spij.minjus.gob.pe/Graficos/Peru/2008/Abril/09/RM-303-2008MTC-02 09-04-08.pdf.

MTC (Ministerio de Transporte y Comunicación). (2010ª). Estudio Definitivo para la Rehabilitación y Mejoramiento de la carretera Ayacucho-Abancay. Tramo: Km 98+800-154+000. Informe Final No 04. Consorcio Abancay Sur y Ministerio de Transportes y Comunicaciones $\backslash$ PROVIAS NACIONAL. Lima/ Perú.

MTC (Ministerio de Transporte y Comunicación). (2010b). Resumen Ejecutivo del Departamento de Cusco de los Proyectos de Construcción Vial; Cusco: DRTC. Perú.

MTC (Ministerio de Transporte y Comunicación). (2018). Manual de carreteras: Diseño Geométrico. DG-2018. RD N 03-2018-MTC/14. Lima. Perú. Recuperado de: https://portal.mtc.gob.pe/transportes/caminos/normas_carreteras/MTC\%20 NORMAS/ARCH_PDF/MAN_1\%20DG-2018.pdf

MINAM (Ministerio del Ambiente). (2009). Decreto Supremo No 019-2009-MINAM: Aprueban el Reglamento de la Ley $N^{0}$ 27446, Ley del Sistema Nacional de Evaluación de Impacto Ambiental. El Peruano, 25(10742): 403208-403208. Lima / Perú. Recuperado de: https://epdoc2.elperuano.pe/EpPo/Descarga. asp? Referencias $=$ TkwyMDA5MDkyNQ $==$.

MINAM (Ministerio del Ambiente). (2011). Ley $\mathrm{N}^{\circ}$ 27446. Ley del Sistema nacional de evaluación de impacto ambiental y Su Reglamento. MINAM. Lima / Perú. https:// www.minam.gob.pe/wp-content/uploads/2013/10/Ley-y-reglamento-del-SEIA1. pdf.

MINAM (Ministerio del Ambiente). (2012). Guía para la identificación y caracterización de impactos ambientales en el marco del Sistema Nacional de Evaluación del Impacto Ambiental. MINAM. Lima. Recuperado de: https://www.minam.gob.pe/ wp-content/uploads/2018/10/Guia-Impactos.pdf. 
MINAM(Ministerio delAmbiente).(2016). Resolución Ministerial $N^{\circ}$ 160-2016-MINAM. Aprobar la culminación del proceso de transferencia de funciones del subsector Transportes del Ministerio de Transportes y Comunicaciones-MTC al Servicio Nacional de Certificación Ambiental para las Inversiones Sostenibles-SENACE. Lima.

MINAM(Ministerio delAmbiente).(2019). Resolución Ministerial N 455-2018-MINAM. Aprueban la Guía para la Elaboración de la Línea Base y la Guía para la identificación y caracterización de impactos ambientales, en el marco del Sistema Nacional de Evaluación del Impacto Ambiental - SEIA. El Peruano, 36(14783): 9-10. 04 de enero de 2019. Lima / Perú. Recuperado de: https://busquedas. elperuano.pe/normaslegales/aprueban-la-guia-para-la-elaboracion-de-la-lineabase-y-la-g-resolucion-ministerial-no-455-2018-minam-1728220-2/.

Ortega, Y. K. \& Capen, D. E. (1999). Effects of forest roads on habitat quality for ovenbirds in a forested landscape. En: The Auk 116(4): 937-946.

Ortolani, E. (1961). Evitación de taludes y protección contra ellos. Editorial CEDEX, Madrid.

Primack, R. (1998). Essentials of conservation biology. 2 ed. Sinaeur. 659p

Reijnen, R.; Foppen, R. and Meeuwsen, H. (1996). The effects of traffic on the density of breeding birds in Dutch agricultural grasslands. En: Biological Conservation 75: 255-260.

Sacher, W. (2013). Informe: Revisión crítica del Estudio de Impacto Ambiental (EIA) del proyecto Mirador de la empresa Ecuacorriente. Ecuador. p. 58.

Sánchez, L.E. (2002). Evaluación de Impacto Ambiental. En: Repetto F.L. \& Karez C.S. (Eds.). Notas de clases dictadas en el II Curso Internacional de Aspectos Geológicos de Protección Ambiental. Campinas, SP - Brasil, del 5 al 20 de junio de 2000. 3670. Recuperado de: https://unesdoc.unesco.org/ark:/48223/pf0000163153.

Secretaría del Convenio sobre la Diversidad Biológica. (2010). Perspectiva Mundial sobre la Biodiversidad. Montreal. p. 94.

Segnestam, L. (2002). Indicators of environment and sustainable development: Theories and practical experience. Environmental Eonomics Series. 89, The World Bank Environment Department.

Walsh Perú. (2006). Estudio de Impacto Socio Ambiental. Proyecto Interconexión Vial Iñapari-Puerto Marítimo del Sur Tramo II. ETAPA I. Lima.

Walsh Perú. (2007). Estudio de Impacto Socio Ambiental (EISA) "Corredor Vial Interoceánico Sur, Perú-Brasil”. Evaluación Biológica. Tramo 2: Urcos-Inambari. Recuperado de: https://repositorio.ana.gob.pe/bitstream/ handle/20.500.12543/3583/ANA0002075 1.pdf? sequence=1\&isAllowed=y. 
Tabla 1.

Determinación del área de influencia directa (AID) e indirecta (AII).

\begin{tabular}{cccccc}
\hline $\begin{array}{c}\text { Longi- } \\
\text { tud (m) }\end{array}$ & $\begin{array}{c}\text { Franja dere- } \\
\text { cha (m) }\end{array}$ & $\begin{array}{c}\text { Franja izquierda } \\
(\mathbf{m})\end{array}$ & AID $\left(\mathbf{K m}^{\mathbf{2}}\right)$ & AII $\left(\mathbf{K m}^{2}\right)$ \\
\hline 29000 & 200 & 200 & $\mathrm{~L}(\mathrm{D}+\mathrm{I})$ & $11.6 \mathrm{Km}^{2}$ & \\
29000 & 400 & 400 & & & $\mathrm{~L}(\mathrm{D}+\mathrm{I}) \quad 23.2 \mathrm{Km}^{2}$ \\
\hline
\end{tabular}

Tabla 2.

Peralte para las curvas en el tramo de estudio comparado con el peralte medido en campo.

\begin{tabular}{|c|c|c|c|c|c|c|c|}
\hline \multirow{3}{*}{$\begin{array}{l}\text { Curva } \\
\mathrm{N}^{\circ}\end{array}$} & \multicolumn{4}{|c|}{ Datos medidos en campo } & \multirow{3}{*}{$\begin{array}{l}\text { Peralte } \\
\text { medido } \\
\text { en cam- } \\
\text { po }(\%)\end{array}$} & \multirow{3}{*}{$\begin{array}{l}\text { Peralte } \\
\text { optimo } \\
\text { calcula- } \\
\text { do }(\%)\end{array}$} & \multirow{3}{*}{ Observaciones } \\
\hline & \multicolumn{2}{|c|}{ Coordenadas } & \multirow{2}{*}{$\begin{array}{l}\text { Ancho de } \\
\text { la vía en } \\
\text { m (A) }\end{array}$} & \multirow{2}{*}{$\begin{array}{l}\text { Radio de } \\
\text { la curva } \\
\text { en } \mathbf{m}(\mathbf{R})\end{array}$} & & & \\
\hline & UTM & $18 \mathrm{~L}$ & & & & & \\
\hline 1 & 8546210 & 0789550 & 7.40 & 27 & 9 & 8.25 & $\begin{array}{l}\text { Falta señalización al } \\
\text { ingresar a la curva. }\end{array}$ \\
\hline 2 & 8547568 & 0789138 & 7.28 & 27.40 & 9 & 7,86 & $\begin{array}{l}\text { Falta señalización al } \\
\text { ingresar a la curva. }\end{array}$ \\
\hline 3 & 8547568 & 0789134 & 7.28 & 27.40 & 9 & 7.86 & $\begin{array}{l}\text { Falta señalización al } \\
\text { ingresar a la curva. }\end{array}$ \\
\hline 4 & 8547662 & 0789064 & 9.50 & 26.70 & 9.5 & 8.54 & $\begin{array}{l}\text { Falta señalización al } \\
\text { ingresar a la curva. }\end{array}$ \\
\hline 5 & 8550932 & 0789034 & 7.28 & 22 & 8 & 14.21 & $\begin{array}{l}\text { Falta señalización al } \\
\text { ingresar a la curva. }\end{array}$ \\
\hline & & & & & & & Mal diseño del peralte \\
\hline 6 & 8550989 & 0788420 & 7.28 & 26.5 & 6 & 9.23 & $\begin{array}{l}\text { Falta señalización al } \\
\text { ingresar a la curva. }\end{array}$ \\
\hline 7 & 8551053 & 0788424 & 7.28 & 28.6 & 6 & 8.47 & $\begin{array}{l}\text { Falta señalización al } \\
\text { ingresar a la curva. }\end{array}$ \\
\hline 8 & 8551398 & 0788410 & 8.5 & 29 & 4 & 8.83 & $\begin{array}{l}\text { Falta señalización al } \\
\text { ingresar a la curva. }\end{array}$ \\
\hline 9 & 8551424 & 0788387 & 8 & 24.5 & 5 & 10.9 & $\begin{array}{l}\text { Falta señalización al } \\
\text { ingresar a la curva. }\end{array}$ \\
\hline 10 & 8552056 & 0788344 & 7.28 & 25 & 9 & 10.34 & $\begin{array}{l}\text { Falta señalización al } \\
\text { ingresar a la curva. }\end{array}$ \\
\hline
\end{tabular}


Tabla 3.

Mensuración de los taludes más riesgosos en el tramo de estudio.

\begin{tabular}{|c|c|c|c|c|c|c|c|}
\hline \multirow[b]{2}{*}{$\underset{\mathbf{N}^{\circ}}{\text { TALUD }}$} & \multirow[b]{2}{*}{ PROGRESIVA } & \multirow{2}{*}{$\begin{array}{l}\text { ELEVACIÓN } \\
\text { (msnm) }\end{array}$} & \multicolumn{2}{|c|}{ COORDENADAS } & \multirow{2}{*}{$\begin{array}{c}\text { LONGITUD } \\
\text { (m) }\end{array}$} & PENDIENTE & \multirow[b]{2}{*}{ OBSERVACIONES } \\
\hline & & & UTM & $18 \mathrm{~L}$ & & (grados) & \\
\hline \multirow[t]{2}{*}{1} & $\mathrm{Km} \mathrm{130+000}$ & 4333 & 8546204 & 0792341 & 27 & 80 & $\begin{array}{l}\text { La cuneta y parte } \\
\text { de la plataforma } \\
\text { vial se encuentra } \\
\text { con material rocoso } \\
\text { y sedimentos. }\end{array}$ \\
\hline & & & & & & & $\begin{array}{l}\text { Falta } \\
\text { señalización. }\end{array}$ \\
\hline 2 & $\mathrm{Km} \mathrm{130+080}$ & 4333 & 8546204 & 0792341 & 47 & 75 y 80 & $\begin{array}{l}\text { La cuneta y parte de } \\
\text { la plataforma vial } \\
\text { se encuentra con } \\
\text { material rocoso y } \\
\text { sedimentos }\end{array}$ \\
\hline & & & & & & & $\begin{array}{l}\text { Se encuentra una } \\
\text { pendiente muy }\end{array}$ \\
\hline 3 & Km 132+933 & 4241 & 8546421 & 0791721 & 55 & 80 y 85 & $\begin{array}{l}\text { alta y material } \\
\text { deleznable }\end{array}$ \\
\hline 4 & $\mathrm{Km} \mathrm{140+134}$ & 3817 & 8547671 & 0791458 & 53 & 67 & $\begin{array}{l}\text { Falta } \\
\text { señalización. }\end{array}$ \\
\hline 5 & $\mathrm{Km} \mathrm{141+800}$ & 3780 & 8547949 & 0789211 & 51 & 82 & $\begin{array}{l}\mathrm{M} \text { a y o r } \\
\text { desprendimiento de } \\
\text { material rocoso y } \\
\text { sedimentos }\end{array}$ \\
\hline 6 & $\mathrm{Km} \mathrm{143+300}$ & 3764 & 8547866 & 0788442 & 118 & 80 y 85 & $\begin{array}{l}\text { Falta } \\
\text { señalización. }\end{array}$ \\
\hline 7 & $\mathrm{Km} \mathrm{143+350}$ & 3730 & 8547870 & 0788842 & 65 & 65 & $\begin{array}{l}\text { Falta } \\
\text { señalización. }\end{array}$ \\
\hline 8 & $\mathrm{Km} \mathrm{147+550}$ & 3543 & 8548969 & 0789783 & 272 & 61 & $\begin{array}{l}\text { Vegetación mínima } \\
\text { y de corto tallo. }\end{array}$ \\
\hline & & & & & & & $\begin{array}{l}\text { Falta } \\
\text { señalización. }\end{array}$ \\
\hline
\end{tabular}




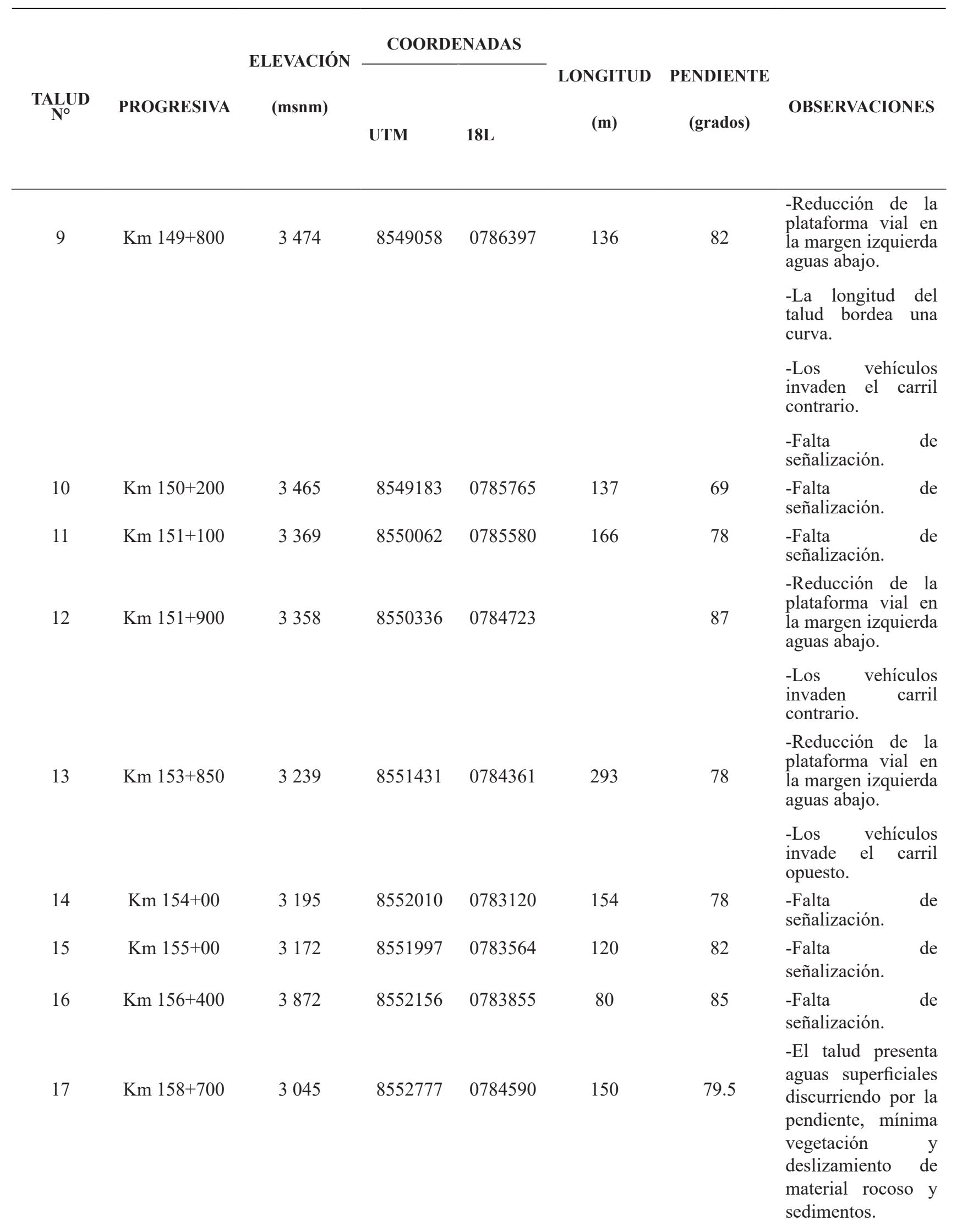




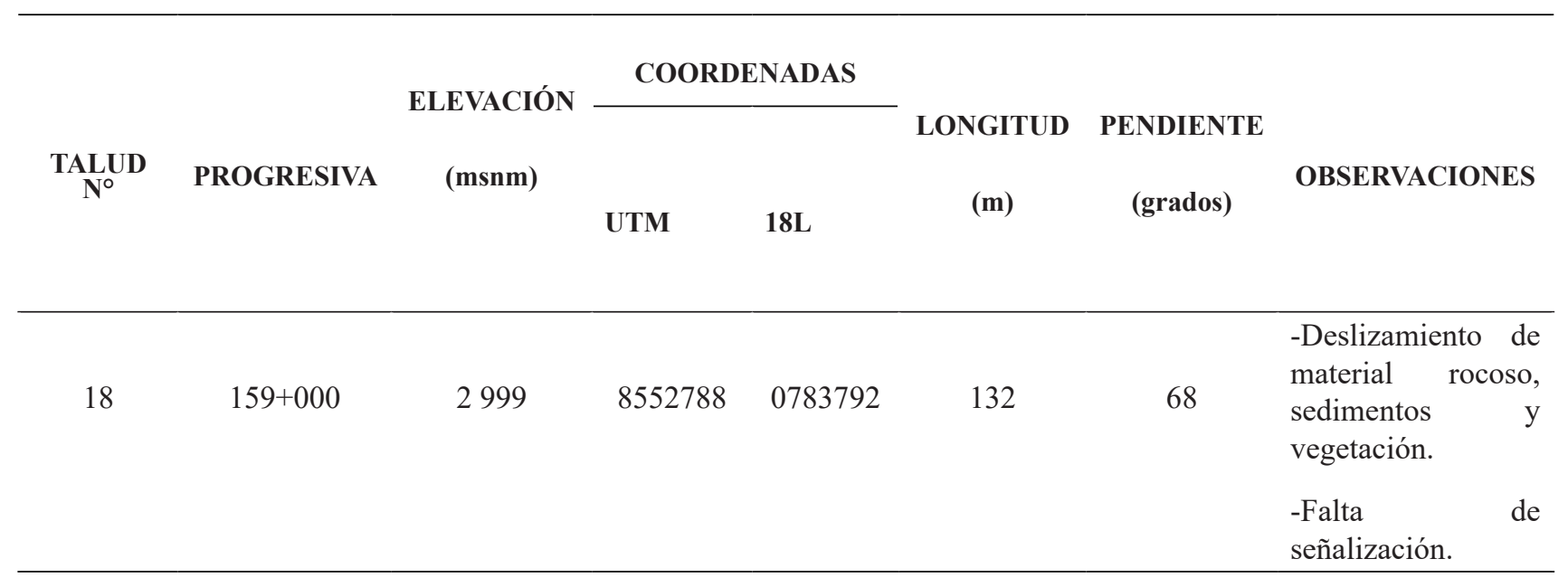

Tabla 4.

Sostenibilidad de las acciones del proyecto en la etapa de funcionamiento.

\begin{tabular}{|c|c|c|c|c|c|c|c|}
\hline \multirow[b]{2}{*}{ Actividades } & \multirow[b]{2}{*}{ Comentarios } & \multirow{2}{*}{ 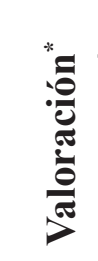 } & \multicolumn{5}{|c|}{ TIPOLOGÍA DEL IMPACTO** } \\
\hline & & & 1 & 2 & 3 & 4 & 5 \\
\hline $\begin{array}{l}\text { Mantenimiento } \\
\text { de la carpeta de } \\
\text { rodadura. }\end{array}$ & $\begin{array}{l}\text { Escasa atención, solo se } \\
\text { ejecuta una vez deteriora- } \\
\text { da. }\end{array}$ & 03 & $\begin{array}{l}\text { Negati- } \\
\text { vo }\end{array}$ & Bajo & $\begin{array}{l}\text { Tempo- } \\
\text { ral }\end{array}$ & $\begin{array}{l}\text { Recuper- } \\
\text { able }\end{array}$ & Moderado \\
\hline $\begin{array}{l}\text { Flujo de trans- } \\
\text { porte fluido. }\end{array}$ & $\begin{array}{l}\text { La carretera es de tránsito } \\
\text { alto, conducen autos, bus- } \\
\text { es, camiones y maquinaria } \\
\text { pesada. }\end{array}$ & 08 & Positivo & Alto & $\begin{array}{l}\text { Perma- } \\
\text { nente }\end{array}$ & $\begin{array}{l}\text { Recuper- } \\
\text { able }\end{array}$ & Moderado \\
\hline $\begin{array}{l}\text { Generación de } \\
\text { ruidos y vibra- } \\
\text { ciones. }\end{array}$ & $\begin{array}{l}\text { Por lo sinuoso de la carret- } \\
\text { era, la falta de señalización } \\
\text { adecuada y las pendientes, } \\
\text { los vehículos usan la boci- } \\
\text { na y los vehículos pesados } \\
\text { usan velocidades bajas, } \\
\text { generando ruidos. }\end{array}$ & 02 & $\begin{array}{l}\text { Negati- } \\
\text { vo }\end{array}$ & Alto & $\begin{array}{l}\text { Perma- } \\
\text { nente }\end{array}$ & Mitigable & Critico \\
\hline $\begin{array}{l}\text { Generación de } \\
\text { PST y gases } \\
\text { tóxicos. }\end{array}$ & $\begin{array}{l}\text { La propia combustión } \\
\text { interna del motor de los } \\
\text { vehículos, especialmente } \\
\text { de Diesel, y la falta de } \\
\text { mantenimiento de la carpe- } \\
\text { ta de rodadura produce el } \\
\text { polvo fugitivo que afecta a } \\
\text { personas, y en época seca } \\
\text { cubre la superficie foliar de } \\
\text { las plantas. }\end{array}$ & 03 & $\begin{array}{l}\text { Negati- } \\
\text { vo }\end{array}$ & $\begin{array}{l}\text { Míni- } \\
\text { mo }\end{array}$ & $\begin{array}{l}\text { Perma- } \\
\text { nente }\end{array}$ & Mitigable & Moderado \\
\hline
\end{tabular}




\begin{tabular}{|c|c|c|c|c|c|c|c|}
\hline \multirow[b]{2}{*}{ Actividades } & \multirow[b]{2}{*}{ Comentarios } & \multirow{2}{*}{ : } & \multicolumn{5}{|c|}{ TIPOLOGÍA DEL IMPACTO** } \\
\hline & & & 1 & 2 & 3 & 4 & 5 \\
\hline $\begin{array}{l}\text { Cortes, taludes e } \\
\text { inestabilidad. }\end{array}$ & $\begin{array}{l}\text { Las pendientes son de- } \\
\text { masiadas altas, consideran- } \\
\text { do la geología inestable; } \\
\text { provoca deslizamientos y } \\
\text { asentamientos. }\end{array}$ & 02 & $\begin{array}{l}\text { Negati- } \\
\text { vo }\end{array}$ & Alto & $\begin{array}{l}\text { Tempo- } \\
\text { ral }\end{array}$ & $\begin{array}{l}\text { Revers- } \\
\text { ible }\end{array}$ & Severo \\
\hline $\begin{array}{l}\text { Manejo del } \\
\text { drenaje (alcan- } \\
\text { tarillas, badenes, } \\
\text { cunetas de coro- } \\
\text { nación, cunetas } \\
\text { laterales, pon- } \\
\text { tones) }\end{array}$ & $\begin{array}{l}\text { En el tramo solo se obser- } \\
\text { va una pequeña cuneta de } \\
\text { coronación, las cunetas } \\
\text { laterales se hallan poco } \\
\text { mantenidas, los pontones } \\
\text { en buen estado. }\end{array}$ & 07 & Positivo & $\begin{array}{l}\text { Míni- } \\
\text { mo }\end{array}$ & $\begin{array}{l}\text { Perma- } \\
\text { nente }\end{array}$ & Mitigable & Critico \\
\hline $\begin{array}{l}\text { Ausencia de } \\
\text { manejo de mi- } \\
\text { crocuencas }\end{array}$ & $\begin{array}{l}\text { En el tramo existen } 16 \text { cur- } \\
\text { sos de agua que en época } \\
\text { de precipitación, y debido } \\
\text { a la pendiente, son torren- } \\
\text { tosos y de alto caudal que } \\
\text { generan erosión con arras- } \\
\text { tre de grandes volúmenes } \\
\text { de sólidos que obstruyen } \\
\text { y destruyen la carpeta as- } \\
\text { fáltica, cunetas y producen } \\
\text { socavamiento de la vía. }\end{array}$ & 01 & $\begin{array}{l}\text { Negati- } \\
\text { vo }\end{array}$ & $\begin{array}{l}\text { Muy } \\
\text { alto }\end{array}$ & $\begin{array}{l}\text { perma- } \\
\text { nente }\end{array}$ & mitigable & Critico \\
\hline $\begin{array}{l}\text { Señalización } \\
\text { inadecuada }\end{array}$ & $\begin{array}{l}\text { Existe escasa y precaria } \\
\text { señalización informativa } \\
\text { y preventiva, tomando en } \\
\text { cuenta que el tramo es una } \\
\text { zona de constante neblina, } \\
\text { alta precipitación y sinu- } \\
\text { osa; es imprescindible la } \\
\text { señalización tanto horizon- } \\
\text { tal como vertical a efecto } \\
\text { de evitar accidentes. }\end{array}$ & 03 & $\begin{array}{l}\text { Negati- } \\
\text { vo }\end{array}$ & $\begin{array}{l}\text { Muy } \\
\text { alto }\end{array}$ & $\begin{array}{l}\text { Perma- } \\
\text { nente }\end{array}$ & Mitigable & Severo \\
\hline $\begin{array}{l}\text { Inadecuado per- } \\
\text { alte }\end{array}$ & $\begin{array}{l}\text { Más del 95\% de las curvas } \\
\text { en "U” no tienen el peralte } \\
\text { adecuado ni el radio de } \\
\text { curva optimo, tampoco } \\
\text { la distancia o recta vial } \\
\text { recomendada; también } \\
\text { carecen de señalización } \\
\text { pertinente, provocando } \\
\text { invasión del carril con- } \\
\text { trario o que el vehículo } \\
\text { sea impelido por la fuerza } \\
\text { centrífuga. }\end{array}$ & 02 & $\begin{array}{l}\text { Negati- } \\
\text { vo }\end{array}$ & $\begin{array}{l}\text { Muy } \\
\text { alto }\end{array}$ & $\begin{array}{l}\text { Perma- } \\
\text { nente }\end{array}$ & Mitigable & Severo \\
\hline
\end{tabular}




\begin{tabular}{|c|c|c|c|c|c|c|c|}
\hline \multirow[b]{2}{*}{ Actividades } & \multirow[b]{2}{*}{ Comentarios } & \multirow{2}{*}{ 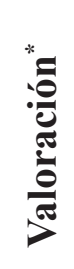 } & \multicolumn{5}{|c|}{ TIPOLOGÍA DEL IMPACTO ** } \\
\hline & & & 1 & 2 & 3 & 4 & 5 \\
\hline Efecto barrera & $\begin{array}{l}\text { Con alto impacto para } \\
\text { mamíferos como el oso } \\
\text { de anteojos, puma, zorro } \\
\text { andino, venado enano, } \\
\text { reptiles, batracios e insec- } \\
\text { tos; no existen pasos para } \\
\text { el movimiento, migración, } \\
\text { búsqueda de alimentos, } \\
\text { apareamiento, nidificación, } \\
\text { etc. }\end{array}$ & 02 & $\begin{array}{l}\text { Negati- } \\
\text { vo }\end{array}$ & Alto & $\begin{array}{l}\text { Perma- } \\
\text { nente }\end{array}$ & Mitigable & Moderado \\
\hline $\begin{array}{l}\text { Carencia de trat- } \\
\text { amiento físico } \\
\text { de taludes. }\end{array}$ & $\begin{array}{l}\text { Inexistencia de terraplenes, } \\
\text { banquetas, muros de con- } \\
\text { tención, cunetas de coron- } \\
\text { ación. }\end{array}$ & 03 & $\begin{array}{l}\text { Negati- } \\
\text { vo }\end{array}$ & Bajo & $\underset{\text { ral }}{\text { Tempo- }}$ & $\begin{array}{c}\text { Revers- } \\
\text { ible }\end{array}$ & Moderado \\
\hline $\begin{array}{l}\text { Vegetación es- } \\
\text { casa. }\end{array}$ & $\begin{array}{l}\text { La ausencia de cobertura } \\
\text { vegetal genera erosión y } \\
\text { arrastre de sólidos a la vía } \\
\text { con deterioro de la infrae- } \\
\text { structura. }\end{array}$ & 03 & $\begin{array}{l}\text { Negati- } \\
\text { vo }\end{array}$ & Alto & $\begin{array}{c}\text { Tempo- } \\
\text { ral }\end{array}$ & $\begin{array}{l}\text { Revers- } \\
\text { ible }\end{array}$ & Severo \\
\hline
\end{tabular}

\begin{tabular}{lr}
\hline * ESCALA DE VALORI \\
Muy favorable: & $10-08$ \\
Favorable: & $07-06$ \\
Sin efecto: & $05-04$ \\
Desfavorables: & $03-01$
\end{tabular}

** TIPOLOGÍA DEL IMPACTO (O ESCALA DE VALORACIÓN)

1: Por las variables de la calidad ambiental (CA)

2: Por la intensidad (grado de destrucción)

3: Por su persistencia.

4: Por su capacidad de recuperación.

5: Por la necesidad de aplicación de medidas correctivas.

\section{CUANTIFICACIÓN O VALORACIÓN EN LA ESCALA}

- Positivo, Negativo.

- Muy alto, Mínimo, Bajo.

- Temporal, Permanente.

- Irreversible, Reversible, Mitigable, Irrecuperable, Recuperable.

- Critico, Severo, Moderado. 
Tabla 5.

Matriz de interacción Causa/Efecto en la etapa de funcionamiento en la vía Cusco-Quillabamba, tramo Abra Malaga-Alfamayo.

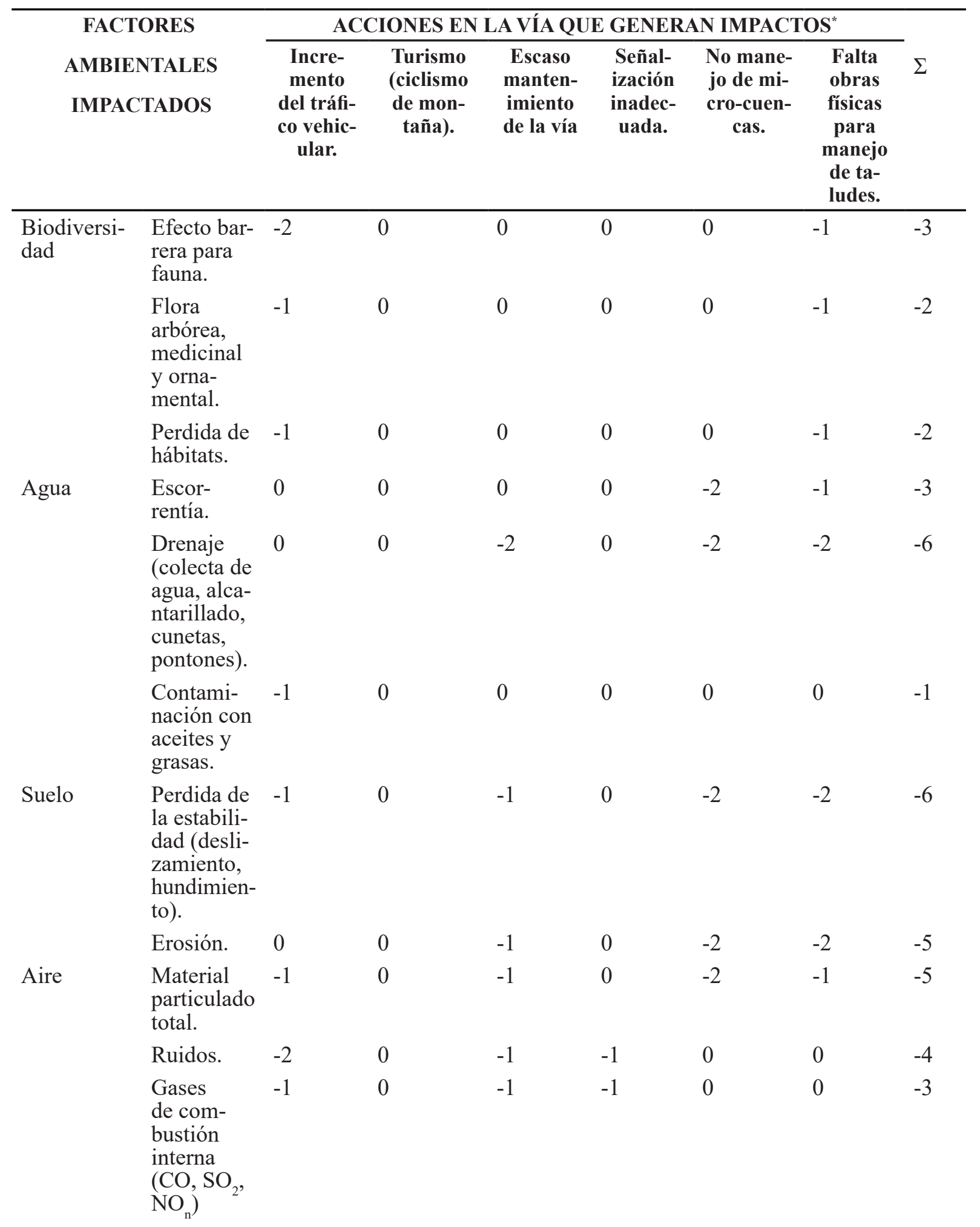




\begin{tabular}{|c|c|c|c|c|c|c|c|c|c|}
\hline \multirow{2}{*}{\multicolumn{3}{|c|}{$\begin{array}{c}\text { FACTORES } \\
\text { AMBIENTALES } \\
\text { IMPACTADOS }\end{array}$}} & \multicolumn{6}{|c|}{ ACCIONES EN LA VÍA QUE GENERAN IMPACTOS* } & \multirow[b]{2}{*}{$\Sigma$} \\
\hline & & & \multirow{2}{*}{$\begin{array}{c}\begin{array}{c}\text { Incre- } \\
\text { mento } \\
\text { del tráfi- } \\
\text { co vehic- } \\
\text { ular. }\end{array} \\
2\end{array}$} & \multirow[t]{2}{*}{$\begin{array}{c}\begin{array}{c}\text { Turismo } \\
\text { (ciclismo } \\
\text { de mon- } \\
\text { taña). }\end{array} \\
1\end{array}$} & \multirow[t]{2}{*}{$\begin{array}{l}\begin{array}{c}\text { Escaso } \\
\text { manten- } \\
\text { imiento } \\
\text { de la vía }\end{array} \\
0\end{array}$} & \multirow[t]{2}{*}{$\begin{array}{c}\begin{array}{c}\text { Señal- } \\
\text { ización } \\
\text { inadec- } \\
\text { uada. }\end{array} \\
0\end{array}$} & \multirow[t]{2}{*}{$\begin{array}{l}\begin{array}{c}\text { No mane- } \\
\text { jo de mi- } \\
\text { cro-cuen- } \\
\text { cas. }\end{array} \\
0\end{array}$} & \multirow[t]{2}{*}{$\begin{array}{c}\begin{array}{c}\text { Falta } \\
\text { obras } \\
\text { físicas } \\
\text { para } \\
\text { manejo } \\
\text { de ta- } \\
\text { ludes. }\end{array} \\
0\end{array}$} & \\
\hline \multirow{8}{*}{$\begin{array}{l}\text { Socio- } \\
\text { económico }\end{array}$} & \multicolumn{2}{|c|}{$\begin{array}{l}\text { Acceso a } \\
\text { servicios. }\end{array}$} & & & & & & & 3 \\
\hline & \multicolumn{2}{|l|}{$\begin{array}{l}\text { Acceso } \\
\text { a infor- } \\
\text { mación. }\end{array}$} & 2 & 1 & 0 & 0 & 0 & 0 & 3 \\
\hline & \multicolumn{2}{|c|}{$\begin{array}{l}\text { Incre- } \\
\text { mentos de } \\
\text { costos de } \\
\text { predios. }\end{array}$} & 2 & 0 & 1 & 0 & 0 & 0 & 3 \\
\hline & \multicolumn{2}{|c|}{$\begin{array}{l}\text { Acceso a } \\
\text { mercados. }\end{array}$} & 2 & 1 & 0 & 0 & 0 & 0 & 3 \\
\hline & \multicolumn{2}{|c|}{$\begin{array}{l}\text { Ahorro de } \\
\text { tiempo. }\end{array}$} & 2 & 2 & 1 & 1 & 0 & 0 & 6 \\
\hline & \multicolumn{2}{|c|}{$\begin{array}{l}\text { Mejora de } \\
\text { los ser- } \\
\text { vicios de } \\
\text { transporte. }\end{array}$} & 2 & 0 & 1 & 1 & 1 & 1 & 6 \\
\hline & \multicolumn{2}{|c|}{$\begin{array}{l}\text { Dinam- } \\
\text { ización } \\
\text { de la } \\
\text { economía } \\
\text { local. }\end{array}$} & 2 & 2 & 1 & 1 & 0 & 1 & 7 \\
\hline & \multicolumn{2}{|l|}{$\begin{array}{l}\text { Gener- } \\
\text { ación de } \\
\text { residuos } \\
\text { sólidos. }\end{array}$} & -1 & -1 & 0 & 0 & 0 & 0 & -2 \\
\hline \multicolumn{3}{|l|}{ Suma } & 03 & 06 & -03 & 01 & -09 & $\mid-09$ & -11 \\
\hline \multicolumn{3}{|c|}{ * Escala } & & & & & & & \\
\hline \multicolumn{2}{|c|}{ Impacto muy favorable } & +2 & & & & & & & \\
\hline \multicolumn{2}{|c|}{ Impacto favorable } & 1 & & & & & & & \\
\hline \multicolumn{2}{|l|}{ Sin impacto } & 0 & & & & & & & \\
\hline \multicolumn{2}{|c|}{ Impacto desfavorable } & -1 & & & & & & & \\
\hline \multicolumn{3}{|c|}{ Impacto muy desfavorable } & & & & & & & \\
\hline
\end{tabular}


Tabla 6.

Matriz de importancia de impactos en fase operativa.

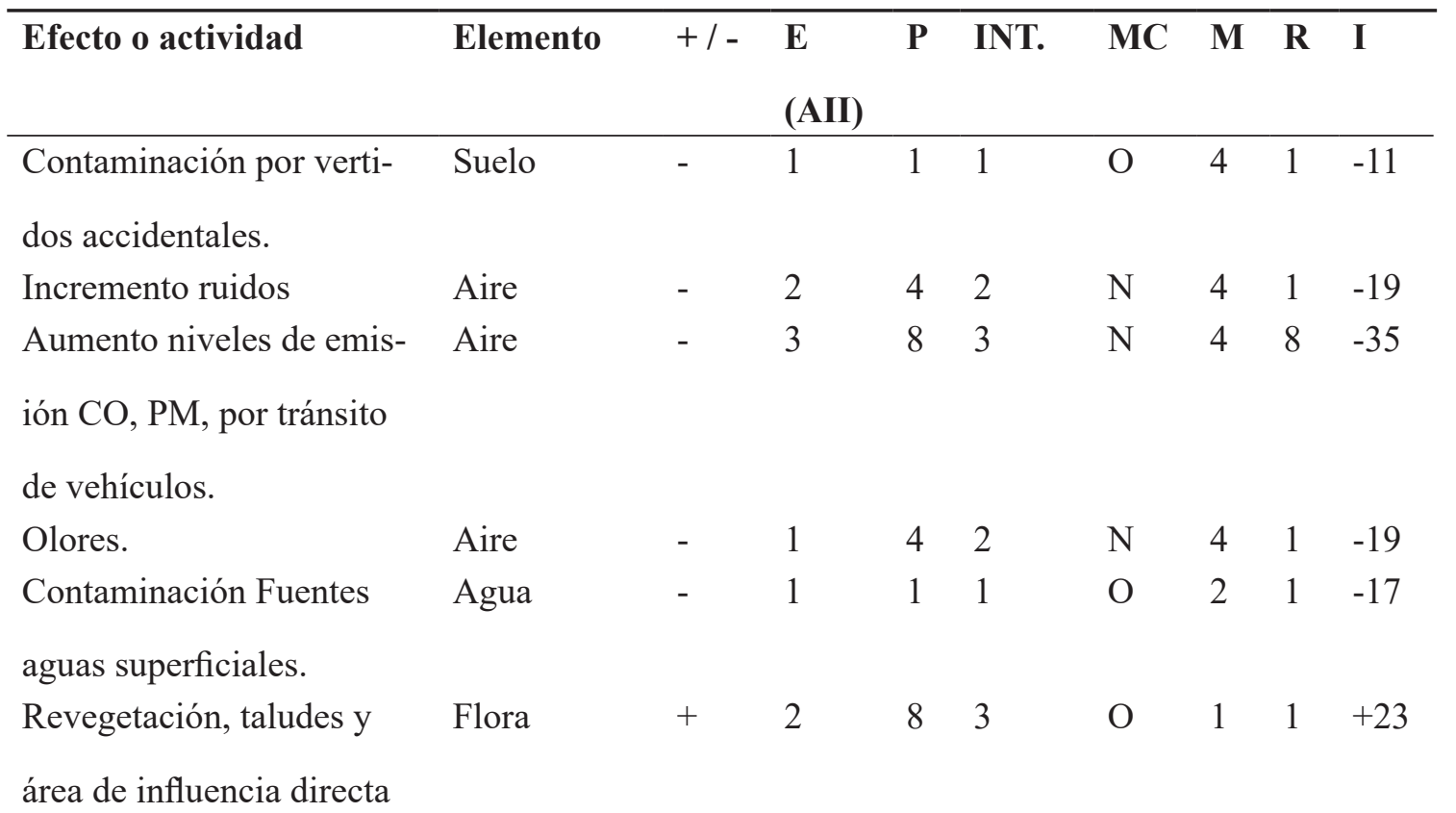

(AID).

O $11+1-$

mográfica.

humano.

11

Modificación paisaje.

Ambiente

$\begin{array}{lll}2 & 8 & 2\end{array}$

$\begin{array}{llll}\mathrm{O} & 4 & 1 & -23\end{array}$

humano.

Aumento fuentes de tra-

Ambiente

$8 \quad 1$

$\begin{array}{llll}\text { O } & 1 & 1 & +15\end{array}$

bajo.

humano.

Riesgos naturales, daño

Ambiente

$8 \quad 1$

$\begin{array}{llll}\text { O } & 4 & 1 & -11\end{array}$

personas u objetos

humano.

Accidentes.

Ambiente

83

$\begin{array}{llll}\mathrm{O} & 1 & 1 & -23\end{array}$

humano.

\footnotetext{
+/- = Mejora o desmejora.

$\mathrm{E}=$ área de influencia: Puntual 1; parcial 2; extensa 3; total 8.

$\mathrm{P}=$ persistencia: Fugaz 1; temporal 2; pertinaz 4; permanente 8.

$\mathrm{MC}=$ medidas correctoras: $\mathrm{O}=$ obras; $\mathrm{N}=$ no hay.

Int. $=$ Grado de incidencia sobre el factor o elemento: Baja 1; Media 2; Alta 3; Muy alta 8, Total 16.

$\mathrm{M}=$ Momento del impacto: Largo plazo 1; mediano 2; inmediato 4.

$\mathrm{R}=$ reversibilidad: Corto plazo 1; medio 3; largo 8; irrecuperable 20 .

$\mathrm{I}=$ Importancia. $+/-[3$ Int. $+2 \mathrm{E}+\mathrm{M}+\mathrm{P}+\mathrm{R}]$.
} 
Tabla 7.

Impactos observados y medidas de mitigación sugeridas en las etapas deoperación y mantenimiento.

\begin{tabular}{|c|c|c|c|}
\hline ACTIVIDAD & IMPACTO & MEDIDA DE MITIGACIÓN & OBSERVACIONES \\
\hline \multirow[t]{6}{*}{ vehicular } & $\begin{array}{l}\text { Contaminación } \\
\text { del suelo y agua }\end{array}$ & $\begin{array}{l}\text { Establecer un programa } \\
\text { permanente de recolección } \\
\text { de residuos sólidos dentro del } \\
\text { derecho de vía, así como la } \\
\text { instalación de contenedores en } \\
\text { sitios estratégicos a lo largo de la } \\
\text { carretera. Realizar campañas de } \\
\text { vigilancia para evitar la formación } \\
\text { de botaderos en el derecho de vía }\end{array}$ & $\begin{array}{l}\text { Se observan botaderos } \\
\text { y cúmulos de residuos } \\
\text { sólidos en el tramo } \\
\text { carretero. }\end{array}$ \\
\hline & $\begin{array}{ll}\text { Riesgo de } \\
\text { accidentes }\end{array}$ & $\begin{array}{l}\text { Establecer un programa } \\
\text { de seguridad que incluya } \\
\text { procedimientos para casos } \\
\text { de emergencia, señalización } \\
\text { e iluminación en lugares } \\
\text { conflictivos, sistemas de } \\
\text { comunicación, etc. }\end{array}$ & Adverso. \\
\hline & $\begin{array}{l}\text { Crecimiento } \\
\text { urbano irregular } \\
\text { a lo largo de } \\
\text { la vera de la } \\
\text { carretera. }\end{array}$ & $\begin{array}{l}\text { Incluir a los organismos de } \\
\text { planificación del uso de suelo en } \\
\text { todos los niveles, en el diseño } \\
\text { y evaluación ambiental de } \\
\text { proyectos, y planear un desarrollo } \\
\text { controlado }\end{array}$ & Adverso \\
\hline & $\begin{array}{l}\text { Incremento en } \\
\text { la demanda } \\
\text { de bienes y } \\
\text { servicios }\end{array}$ & $\begin{array}{l}\text { Existe un mayor número de } \\
\text { personas utilizando el servicio } \\
\text { en el tramo; además, una mayor } \\
\text { demanda por servicios de } \\
\text { transporte de carga. }\end{array}$ & Benéfico \\
\hline & $\begin{array}{l}\text { Contaminación } \\
\text { del aire }\end{array}$ & $\begin{array}{l}\text { Establecer un programa de } \\
\text { reforestación a fin de compensar } \\
\text { la contaminación por emisiones } \\
\text { de material particulado y gases. }\end{array}$ & Adverso \\
\hline & $\begin{array}{l}\text { Contaminación } \\
\text { por ruido }\end{array}$ & $\begin{array}{l}\text { Colocar barreras vegetales } \\
\text { (reforestación). }\end{array}$ & Adverso \\
\hline
\end{tabular}

En casos específicos deberá analizarse la necesidad de construir barreras con materiales absorbentes de ruido, pudiendo utilizarse el excedente de la excavación para formar barreras en zonas urbanas

Reducir el tránsito pesado en horario nocturno en zonas urbanas 
Mantenimiento y Conservación

Contaminación del agua superficial y subterránea y desequilibrio ecológico tapar grietas.

Contaminación del aire de velocidad de operación en zonas urbanas.

Generación de empleo

Riesgo de accidentes temporal y permanente.
Establecer un programa de limpieza y desazolve de cunetas

Retirar escombros

Control del manejo de combustibles y lubricantes y derivados de asfalto por personal técnico especializado para evitar fugas.

Construir obras de drenaje necesarias para mantener el patrón hidrológico superficial.

Limpiar vegetación herbácea en el canal, inspeccionar pintura y

Adverso

Reforestar los claros y partes altas con flora nativa de la zona..

Cubrir con lona los materiales transportados en fase húmeda.

La etapa de operación y mantenimiento genera empleo

Benéfico.

Contar con los dispositivos de

Adverso señalamiento adecuados y hasta donde sea posible hacerlo en las horas de menor tránsito vehicular, limitando la longitud al mínimo operativo. 
Inspeccionar las condiciones de cables, vigas,

cimientos, etc., de puentes al menos cada dos años.
Contaminación y erosión del suelo

Evitar el uso de herbicidas e insecticidas para la limpieza del derecho de vía.

Construir bermas, suavizar cortes a manera de restringir la superficie de afectación.

Recuperar el total de los materiales producto del desmonte y despalme de los bancos de préstamo laterales para trabajos de arrope de taludes y disponer sobre la superficie afectada.

\section{Adverso}

Inducir a los procesos de sucesión natural in situ

Tabla 8.

Medidas correctivas para el manejo de taludes.

\begin{tabular}{|c|c|c|c|c|c|}
\hline \multirow{2}{*}{$\begin{array}{l}\text { SEC- } \\
\text { TOR No }\end{array}$} & \multicolumn{2}{|c|}{ COORDENADAS } & \multirow{2}{*}{$\begin{array}{l}\text { PEND- } \\
\text { IENTE } \\
\text { (grados) }\end{array}$} & \multirow{2}{*}{$\begin{array}{l}\text { CARACTERÍSTICAS Y } \\
\text { DESCRIPCIÓN }\end{array}$} & \multirow{2}{*}{$\begin{array}{l}\text { MEDIDAS CORRECTI- } \\
\text { VAS PROPUESTAS }\end{array}$} \\
\hline & UTM & $18 \mathrm{~L}$ & & & \\
\hline 1 & 8546204 & 0792341 & 80 & $\begin{array}{l}\text { Deslizamiento de mate- } \\
\text { rial rocoso y sedimentos } \\
\text { colapsando cunetas e } \\
\text { invadiendo parte de la } \\
\text { plataforma vial. }\end{array}$ & $\begin{array}{l}\text { Construcción de gaviones, } \\
\text { terraplenes, cunetas de } \\
\text { coronación, limpieza de } \\
\text { cunetas, revegetación na- } \\
\text { tiva y colocar señalización } \\
\text { informativa y preventiva. }\end{array}$ \\
\hline 2 & 8546204 & 0792341 & 75 y 80 & $\begin{array}{l}\text { Deslizamiento de mate- } \\
\text { rial rocoso y sedimentos } \\
\text { colapsando cunetas e } \\
\text { invadiendo parte de la } \\
\text { plataforma vial. }\end{array}$ & $\begin{array}{l}\text { Construcción de gaviones, } \\
\text { terraplenes, limpieza de } \\
\text { las cunetas, revegetar y } \\
\text { colocar señalización in- } \\
\text { formativa y preventiva. }\end{array}$ \\
\hline 3 & 8547671 & 0789211 & 67 & $\begin{array}{l}\text { Deslizamiento de mate- } \\
\text { rial rocoso y sedimen- } \\
\text { tos. }\end{array}$ & $\begin{array}{l}\text { Construcción de gavi- } \\
\text { ones, revegetar y colocar } \\
\text { señalización informativa y } \\
\text { preventiva. }\end{array}$ \\
\hline 4 & 8547949 & 0788442 & 82 & $\begin{array}{l}\text { Deslizamiento de mate- } \\
\text { rial rocoso y sedimen- } \\
\text { tos. }\end{array}$ & $\begin{array}{l}\text { Construcción de gavi- } \\
\text { ones, revegetar y colocar } \\
\text { señalización informativa y } \\
\text { preventiva. }\end{array}$ \\
\hline 5 & 8547866 & 0788842 & 70 y 80 & $\begin{array}{l}\text { Deslizamiento de mate- } \\
\text { rial rocoso, vegetación } \\
\text { y sedimentos. }\end{array}$ & $\begin{array}{l}\text { Construcción de gaviones, } \\
\text { construcción de terra- } \\
\text { plenes, revegetar y colo- } \\
\text { car señalización informa- } \\
\text { tiva y preventiva. }\end{array}$ \\
\hline
\end{tabular}




\begin{tabular}{|c|c|c|c|c|c|}
\hline \multirow{2}{*}{$\begin{array}{l}\text { SEC- } \\
\text { TOR No }\end{array}$} & \multicolumn{2}{|c|}{ COORDENADAS } & \multirow{2}{*}{$\begin{array}{l}\text { PEND- } \\
\text { IENTE } \\
\text { (grados) }\end{array}$} & \multirow{2}{*}{$\begin{array}{l}\text { CARACTERÍSTICAS Y } \\
\text { DESCRIPCIÓN }\end{array}$} & \multirow{2}{*}{$\begin{array}{l}\text { MEDIDAS CORRECTI- } \\
\text { VAS PROPUESTAS }\end{array}$} \\
\hline & UTM & $18 \mathrm{~L}$ & & & \\
\hline 6 & 8547870 & 0789783 & 85 & $\begin{array}{l}\text { Deslizamiento de mate- } \\
\text { rial rocoso, vegetación } \\
\text { y sedimentos. }\end{array}$ & $\begin{array}{l}\text { Construcción de gaviones, } \\
\text { construcción de terra- } \\
\text { plenes, revegetar y colo- } \\
\text { car señalización informa- } \\
\text { tiva y preventiva. }\end{array}$ \\
\hline 7 & 8548969 & 0786397 & 61 & $\begin{array}{l}\text { Deslizamiento de mate- } \\
\text { rial rocoso, vegetación } \\
\text { y sedimentos. } \\
\text { Área en peligro. }\end{array}$ & $\begin{array}{l}\text { Construcción de gaviones, } \\
\text { construcción de terra- } \\
\text { plenes, revegetar y colo- } \\
\text { car señalización informa- } \\
\text { tiva y preventiva. }\end{array}$ \\
\hline 8 & 8549058 & 0785765 & 82 & $\begin{array}{l}\text { Reducción de la plata- } \\
\text { forma vial y desli- } \\
\text { zamiento de material } \\
\text { rocoso, vegetación y } \\
\text { sedimentos. } \\
\text { Pendiente bordea una } \\
\text { curva, falta de área de } \\
\text { estacionamiento. }\end{array}$ & $\begin{array}{l}\text { Construcción de gaviones } \\
\text { y terraplenes, reveg- } \\
\text { etación. } \\
\text { Construir muros de con- } \\
\text { tención del lado izquierdo } \\
\text { aguas abajo de la zona y } \\
\text { colocar señalización in- } \\
\text { formativa y preventiva. }\end{array}$ \\
\hline 9 & 8549183 & 0785580 & 69 & $\begin{array}{l}\text { Deslizamiento de mate- } \\
\text { rial rocoso, vegetación } \\
\text { y sedimentos. }\end{array}$ & $\begin{array}{l}\text { Construcción de gaviones } \\
\text { y terraplenes, reveg- } \\
\text { etación y colocar señal- } \\
\text { ización informativa y } \\
\text { preventiva en la zona. }\end{array}$ \\
\hline 10 & 8550062 & 0784723 & 78 & $\begin{array}{l}\text { Deslizamiento de mate- } \\
\text { rial rocoso, vegetación } \\
\text { y sedimentos. }\end{array}$ & $\begin{array}{l}\text { Construcción de gaviones } \\
\text { y terraplenes, reveg- } \\
\text { etación y colocar señal- } \\
\text { ización informativa y } \\
\text { preventiva. }\end{array}$ \\
\hline 11 & 8550336 & 0784361 & 87 & $\begin{array}{l}\text { Reducción de la plata- } \\
\text { forma vial; deslizamien- } \\
\text { to de material rocoso, } \\
\text { vegetación y sedimen- } \\
\text { tos. Pendiente bordea } \\
\text { una curva, falta de área } \\
\text { de estacionamiento. }\end{array}$ & $\begin{array}{l}\text { Construcción de gaviones } \\
\text { y terraplenes, reveg- } \\
\text { etación. } \\
\text { Construir muros de con- } \\
\text { tención del lado izquierdo } \\
\text { aguas abajo de la zona y } \\
\text { colocar señalización in- } \\
\text { formativa y preventiva. }\end{array}$ \\
\hline 12 & 8551431 & 0783120 & 78 & $\begin{array}{l}\text { Deslizamiento de mate- } \\
\text { rial rocoso, vegetación } \\
\text { y sedimentos. Este talud } \\
\text { se encuentra en una } \\
\text { curva. }\end{array}$ & $\begin{array}{l}\text { Revegetación y colocar } \\
\text { señalización informativa y } \\
\text { preventiva. }\end{array}$ \\
\hline 13 & 8552010 & 0783564 & 75 & $\begin{array}{l}\text { Deslizamiento de mate- } \\
\text { rial rocoso, vegetación } \\
\text { y sedimentos. }\end{array}$ & $\begin{array}{l}\text { Construcción de gaviones } \\
\text { y revegetación; colocar } \\
\text { señalización informativa y } \\
\text { preventiva. }\end{array}$ \\
\hline 14 & 8551997 & 0783855 & 82 & $\begin{array}{l}\text { Deslizamiento de mate- } \\
\text { rial rocoso, vegetación } \\
\text { y sedimentos. }\end{array}$ & $\begin{array}{l}\text { Construcción de gaviones, } \\
\text { revegetación de la zona y } \\
\text { colocar señalización in- }\end{array}$ \\
\hline & & & & $\begin{array}{l}\text { Material rocoso sobre } \\
\text { saliente en la parte su- } \\
\text { perior del talud. }\end{array}$ & \\
\hline
\end{tabular}




\begin{tabular}{|c|c|c|c|c|c|}
\hline \multirow{2}{*}{$\begin{array}{l}\text { SEC- } \\
\text { TOR No }\end{array}$} & \multicolumn{2}{|c|}{ COORDENADAS } & \multirow{2}{*}{$\begin{array}{l}\text { PEND- } \\
\text { IENTE } \\
\text { (grados) }\end{array}$} & \multirow{2}{*}{$\begin{array}{l}\text { CARACTERÍSTICAS Y } \\
\text { DESCRIPCIÓN }\end{array}$} & \multirow{2}{*}{$\begin{array}{l}\text { MEDIDAS CORRECTI- } \\
\text { VAS PROPUESTAS }\end{array}$} \\
\hline & UTM & $18 \mathrm{~L}$ & & & \\
\hline 15 & 8552156 & 0784590 & 85 & $\begin{array}{l}\text { Deslizamiento de mate- } \\
\text { rial rocoso, vegetación } \\
\text { y sedimentos. }\end{array}$ & $\begin{array}{l}\text { Revegetación de la zona y } \\
\text { colocar señalización in- } \\
\text { formativa y preventiva. }\end{array}$ \\
\hline 16 & 8552777 & 0783792 & 79.5 & $\begin{array}{l}\text { Deslizamiento de mate- } \\
\text { rial rocoso, vegetación } \\
\text { y sedimentos. Se obser- } \\
\text { va aguas superficiales } \\
\text { discurriendo por la pen- } \\
\text { diente. }\end{array}$ & $\begin{array}{l}\text { Construcción de cunetas } \\
\text { de coronación en la parte } \\
\text { alta del talud, construc- } \\
\text { ción de gaviones y ter- } \\
\text { raplenes, revegetación y } \\
\text { señalización informativa y } \\
\text { preventiva. }\end{array}$ \\
\hline 17 & 8552788 & 0783164 & 68 & $\begin{array}{l}\text { Deslizamiento de mate- } \\
\text { rial rocoso, vegetación, } \\
\text { sedimentos y veg- } \\
\text { etación. }\end{array}$ & $\begin{array}{l}\text { Construcción de gaviones, } \\
\text { revegetación y colocar } \\
\text { señalización informativa y } \\
\text { preventiva. }\end{array}$ \\
\hline
\end{tabular}

Tabla 9.

Impactos positivos y negativos según matriz utilizada para medir impactos ambientales del tramo de estudio.

\begin{tabular}{lccccccc}
\hline \multicolumn{1}{c}{ Método EIA } & \multicolumn{3}{c}{ Número de Impactos } & \multicolumn{2}{c}{ Variables ambientales } \\
& \multicolumn{3}{c}{ ambientales } & \multicolumn{2}{c}{ evaluadas } \\
\cline { 2 - 8 } & positivo & $\mathbf{\%}$ & Negativo & $\mathbf{\%}$ & Número & \% \\
\hline Tipología de impactos & 02 & 17 & 10 & 83 & 12 & 100 \\
Matriz Causa/efecto & 07 & 37 & 12 & 63 & 19 & 100 \\
Matriz de importancia & 03 & 27 & 08 & 73 & 11 & 100
\end{tabular}


Figura 1

Ubicación del tramo carretero

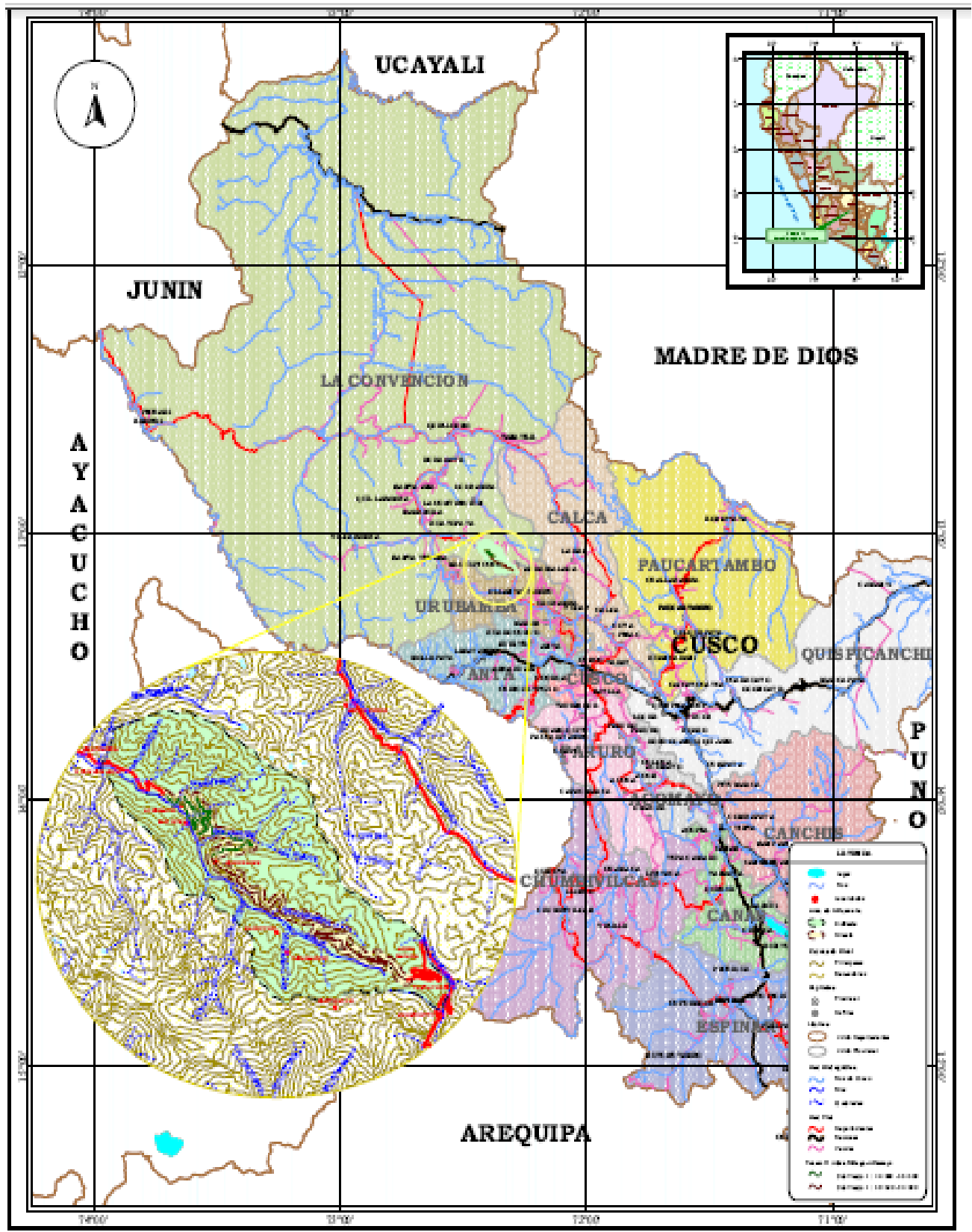

Fuente. Elaborado en base a la Carta Nacional, escala 1:100 000 


\section{Figura 2}

Determinación del área de influencia directa (AID) y del área de influencia indirecta (AII) del tramo carretero Abra de Málaga-Alfamayo
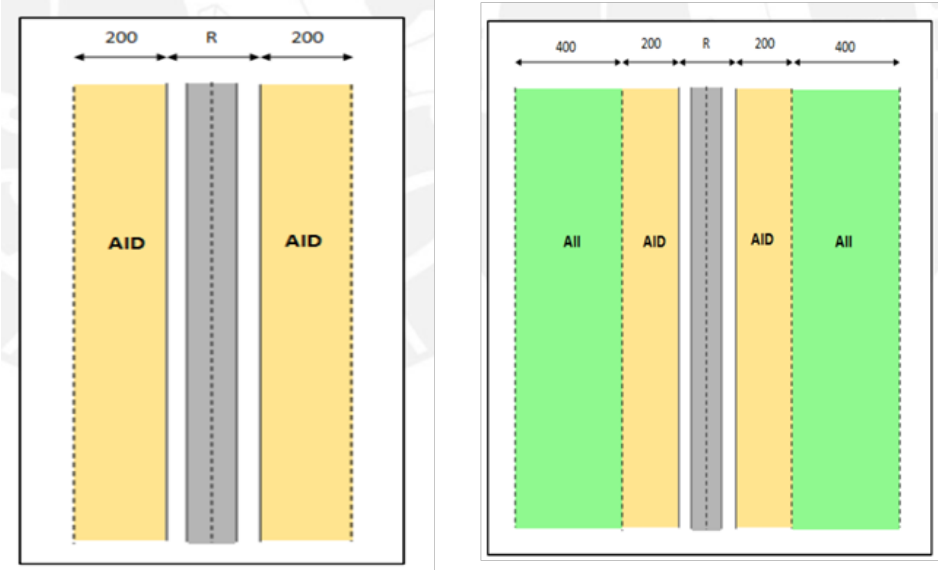

Fuente. Elaborado en base a información de la Tabla 1

\section{Figura 3}

Hoja de campo 4. Tramo: Abra Málaga-Alfamayo. Progresiva: Km. $140+134$

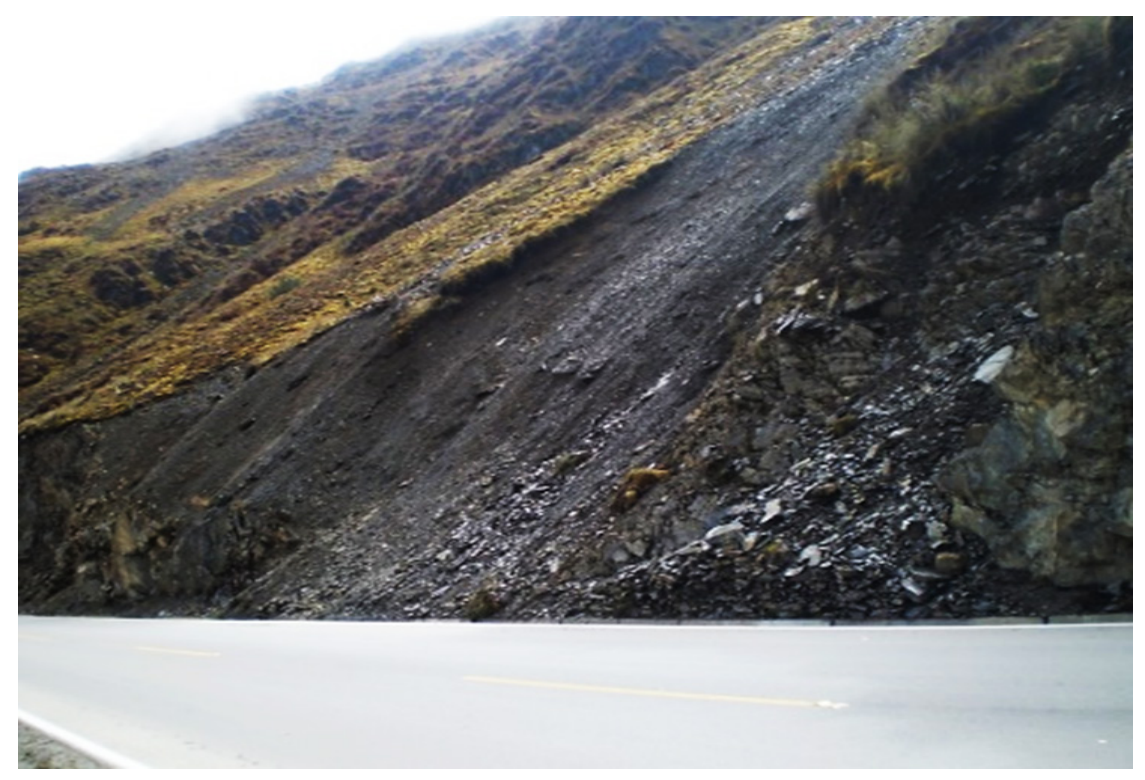




\section{Figura 4}

Hoja de campo 14. Tramo: Abra Málaga-Alfamayo. Progresiva: Km. $158+700$

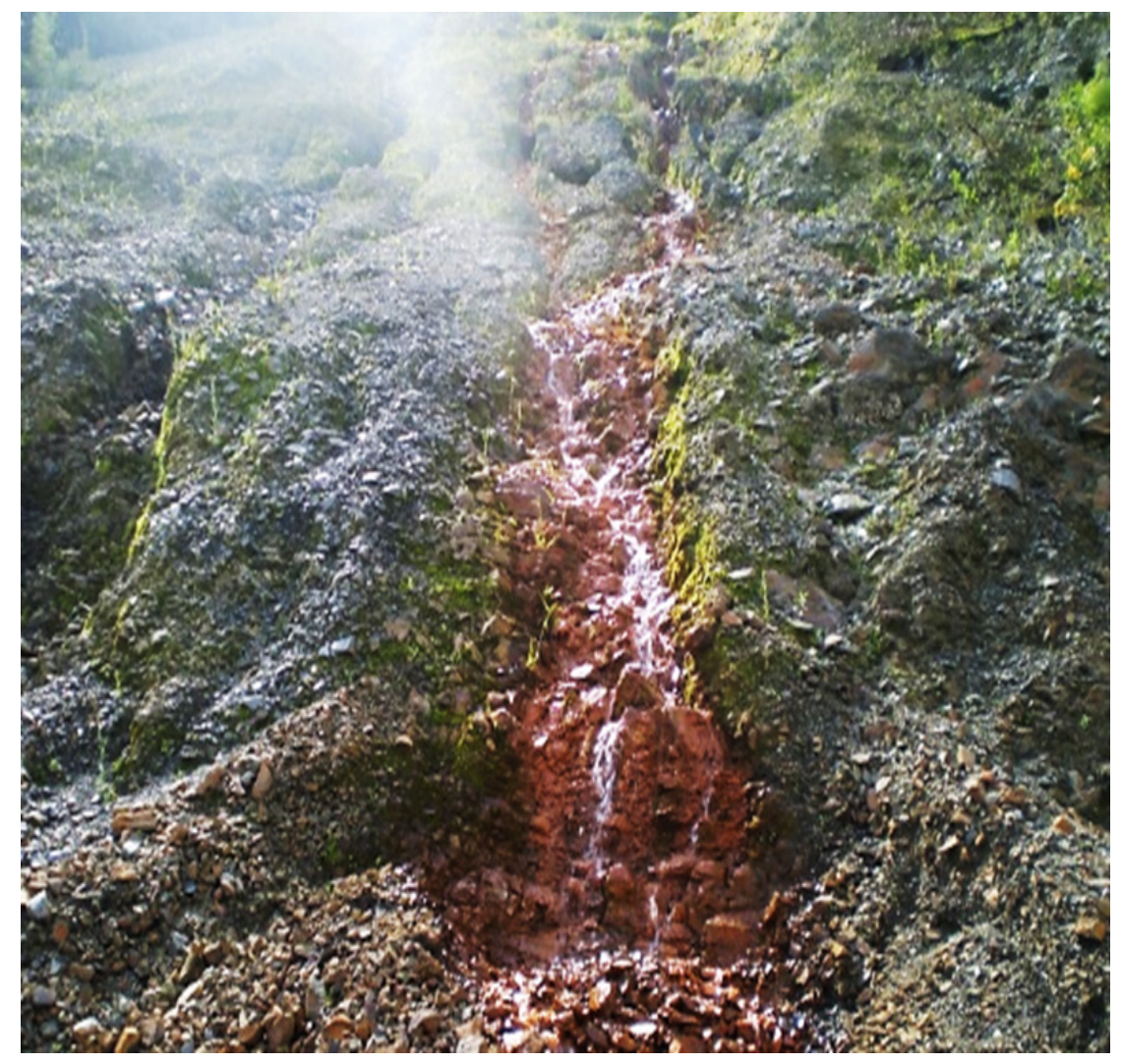


Figura 5.

Árbol de problemas en inestabilidad de taludes

Incidencia en los accidentes de tránsito en la vía

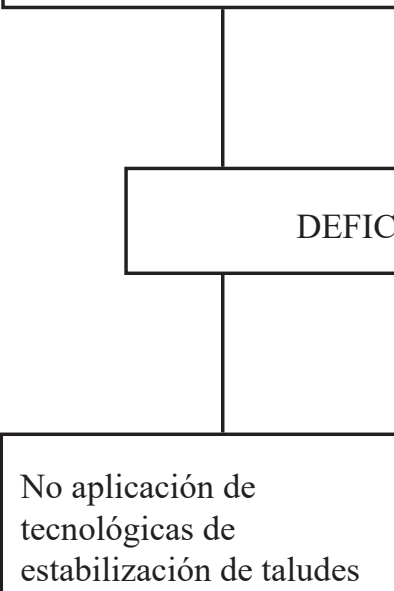

Incidencia en

Desplazamientos
Incidencia en

diaclasamiento de rocas

EFICIENTE TRATAMIENTO DE SUELOS Y VEGETACIÓN

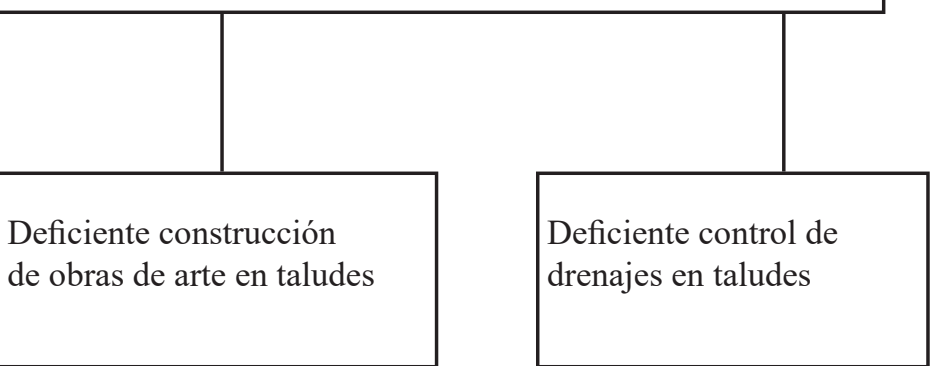

